\title{
Recurrent Spontaneous Seizure State Induced by Prefrontal Kindling in Senegalese Baboons, Papio Papio
}

\author{
J. A. WADA, T. OSAWA AND T. MIZOGUCHI
}

SUMMARY: In our earlier study of amygdaloid kindling in Papio papio $(P p)$, the development of partial complex seizure and of focal motor seizure was correlated with bifrontal theta discharge and increasing Rolandic spike discharge respectively and the final stage was characterized by primary generalized convulsive seizure. Since the latter seizure pattern is known to originate from the frontal focus in man, the frontal cortex became suspect in the development of the final stage seizure pattern. Daily prefrontal stimalation showed that $P p$ can be kindled from this site, culminating in a recurrent spontaneous seizure

RÉSUMÉ: Des stimulations préfrontales journalieres montrent que le "kindling" peut être produit chez le papio papio à partir de ce site, créant un état de convalsions récurrentes spontanées identique à celui produit dans la même espèce par "kindling" amygdalien. Cependant les "kindling" préfrontaux et state identical to that induced by amygdaloid kindling in this species. However, our observation did not support our original assumption regarding the genesis of primary generalized convulsive seizure. Prefrontal and amygdaloid kindling are significantly different with respect to morphology, distribution and propagation of afterdischarge and interictal spike discharge, and speed and pattern of clinical seizure development. Most intriguingly, inter-ictal behavioral aberration associated with depth EEG changes was observed only in the prefrontal animals and not in the amygdaloid animals.

amygdaliens sont significativement différents quant à leur morphologie, à la distribution et à la propagation des postdécharges et des décharges en pointe intérictales, et enfin quant à la vitesse et au pattern de développement de la crise clinique.
Reprint requests to Dr. J. A. Wada, Division of Neurological Sciences, University of British Columbia, 2075 Westbrook Place, Vancouver, Canada V6T IW5.

From the Division of Neurological Sciences, Faculty of Medicine, University of British Columbia.

This work is supported by grants from Canadian Medical Research Council and U.S. National Institute of Neurological, Communicative Disease and Stroke awarded to J. A. Wada.
In our previous study of amygdaloid kindling in epileptic Senegalese baboons, Papio papio, we found that they reached a final stage of generalized convulsion which was characterized by the onset of a bisymmetrical clonictonic-clonic seizure associated with bisynchronous electrographic discharge beginning in the bulbar reticular formation (Wada \& Osawa, 1975). These electroclinical manifestations were identical to those of the spontaneous recurrent primary generalized convulsions observed in amygdaloid kindled baboons. In addition this pattern was strikingly similar to the pattern of the photically induced generalized convulsion in this species (Wada, Terao \& Booker, 1972). In amygdaloid kindling of rhesus monkeys only secondary generalized convulsive seizures were observed in spite of the substantially larger number of daily stimulations given ((Goddard, McIntyre \& Leech, 1969; Wada \& Mizoguchi, unpublished data). This finding suggests a unique predisposition of Papio papio toward primary generalized seizures. If this assumption is correct, one could expect this species (Papio papio) to respond similarly to a kindling procedure involving other brain sites.

However, the clinically known fact that epileptogenic lesions in the frontal polar region generate generalized convulsions comparable to primary generalized seizures (Rasmussen, 1975; Goldring, 1972) suggests the possibility that the primary generalized seizures observed in amygdaloid kindled baboons may be due in part to secondary activation of this cortical area. Indeed, electrographic evidence of an early participation of anterior 
frontal cortical areas in amygdaloid seizure development has been observed in both cats and baboons (Wada, Sato \& McCaughran), (In press).

This is not unexpected since the frontal cortex is known to receive projections from the amygdala either directly (Kretteck \& Price, 1974) or via the medialis dorsalis of the thalamus (Nauta, 1962). Therefore, we examined the possibilities that primary generalized seizures in Papio papio result (1) from secondary activation of the frontal cortex, or (2) through a unique epileptogenic predisposition of this species.

The results of the present study show that a recurrent spontaneous convulsive seizure state identical to that observed among amygdaloid kindled baboons also can be induced by kindling this neocortical site. However, the findings do not support an assumption that the primary generalized convulsive seizure pattern of AM kindled animals results from secondary ictal activation of the prefrontal cortex (PF). Rather, the findings reinforce our concept that Papio papio is a unique subhuman primate model of human epilepsy with a predisposed susceptibility towards primary generalized seizure.

\section{MATERIALS AND METHODS}

Two Senegalese baboons, a $6.2 \mathrm{~kg}$ male (W135) and a $5.7 \mathrm{~kg}$ female (W136), were used. These animals were followed for a period of three and a half years with respect to their photosensitivity prior to the implantation of electrodes. Neither of them was witnessed to have spontaneous convulsive seizures. Permanent electrodes were implanted under sodium pentobarbital anesthesia $(35 \mathrm{mg} / \mathrm{kg}$ ). Bipolar cortical and depth recording electrodes were made by attaching a stainless steel wire, $0.19 \mathrm{~mm}$ diameter, to No. 30 stainless steel tubing insulated except for the tips, with an interelectrode distance of $1 \mathrm{~mm}$. The stimulating electrode was the same stainless steel wire insulated except for $2 \mathrm{~mm}$ at the tip, and was attached to the cortical recording electrode. The latter was placed bilaterally over the dorsal surface of the frontal lobe. The exposed portion of the stimulating cortical electrode was inserted perpendicularly into the prefrontal cortex (PF). Depth electrodes were placed into the basal lateral amygdala (AM), caudate nucleus (CD), globus pallidus (GP), mesencephalic reticular formation (MRF), substantia nigra ( $\mathrm{SN}$ ), bulbar reticular formation (BRF), dorsomedial nucleus of thalamus (MD), putamen (PUT), hypothalamus (HYPO), and hippocampus (HIPP). One month elapsed following surgery before commencement of the PF stimulation.

The animals were permanently housed in the Vancouver Behavioral Observation Box (Wada, 1961) and the electroencephalogram was recorded on a 16 channel Grass machine. PF stimulation was delivered not less than 10 minutes after the animal had assumed a resting posture subsequent to commencement of monitoring. Following the stimulation the recording continued for at least 10 to 15 minutes. Stimulation was administered twice a day with 6 to 10 hour intervals, the first stimulation being between 8 a.m. and 11 a.m., and the second stimulation between 4 p.m. and 6 p.m.

Left (W135) or right (W136) PF stimulation with $60 \mathrm{~Hz}$ sine wave lasting for 1 second was delivered monopolarly. The intensity of the stimulation was regulated by a constant current unit. Stimulation intensity was initially set at $100 \mu \mathrm{a}$, with subsequent daily increases of $100 \mu$ a until a sustained afterdischarge (AD) localized to the stimulated cortical site was elicited. On each subsequent day the stimulation intensity was reduced by 100 $\mu$ a until AD could no longer be elicited. the last intensity that produced AD was arbitrarily designated as the AD threshold; the stimulation intensity during the kindling procedure was set at $\mathrm{AD}$ threshold. When the final stage generalized convulsive seizure developed, the stimulation was repeated for 5 more days. On each subsequent day the stimulation intensity was reduced by $5 r^{\prime} \mu$ a until the animal ceased to respond with a generalized convulsive seizure. The stimulation intensity on the day before the disappearance of the electroclinical ictal response was arbitrarily designated as the generalized seizure triggering threshold (GST).

Assessment of photosensitivity between the implantation of electrodes and commencement of the kindling procedure was done weekly for 3-5 weeks using a Grass photostimulator set at intensity 16 and $20-25 \mathrm{~Hz}$. Photic stimulation was presented during three to five 3-minute sessions separated by 20-minute intervals. The results of these examinations showed no deviation from the results of the previous chronological examinations in both animals. Similar examinations were performed following completion of the final stage of seizure development. The clinical response to

Figure 1-Chronology of seizure development and AD growth.
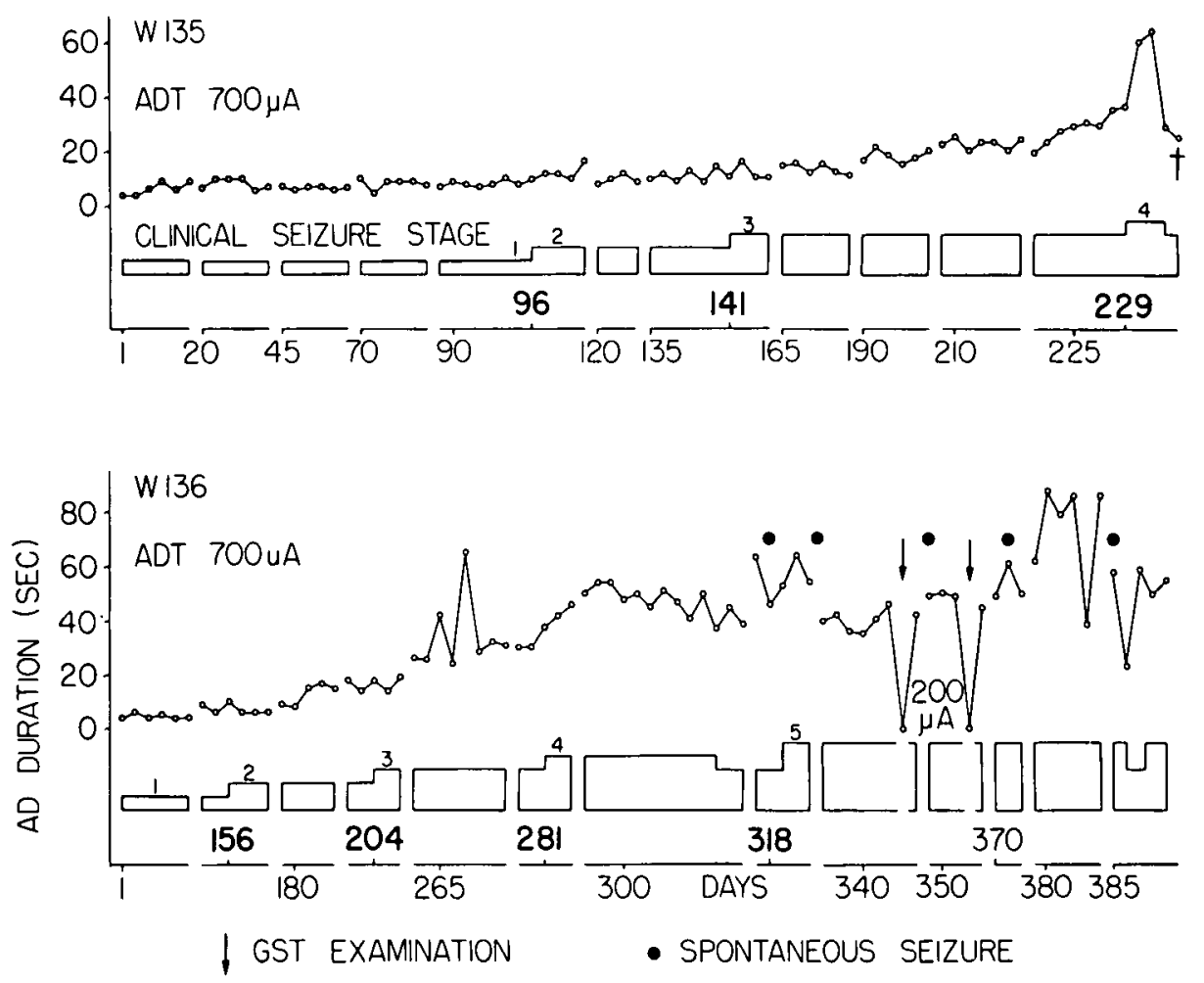
photic stimulation was documented as described previously (Wada, Terao \& Booker, 1972), that is: $\mathrm{CO}=$ no response, $\mathrm{c}+1=$ twitching of eyelids, $C+2=1$ witching of the face and hand, $C+3=$ twitching of the body and/or limbs. None of the animals developed a sustained generalized convulsive seizure as a result of photic stimulation.

One animal (W135) died from acute small bowel obstruction shortly after reaching Stage 4 . Histological examination of this animal's brain showed that the stimulating electrode was at the anterior end of the inferior bank of the principal sulcus, and that all the recording electrodes were localized in the intended sites except for the BRF electrodes which were found in the cerebellar peduncle. The other animal (W136) is still maintained for further studies.

\section{RESULTS}

(A) Clinical Seizure Development: The chronology of seizure development is summarized in Figure $I$ and details are given below. During PF stimulation, ipsilateral head-turning and a generalized tonic posturing was observed. Immediately upon termination of the stimulation the animals showed one or two jerky movements of the entire body. The pattern of seizure development has been classified into the following 5 stages.

Stage 1. Arrest of ongoing behavior with occasional ipsilateral head turning: Initially there was very little overtly identifiable behavior. As stimulation was repeated the animal began to show an apathetic but somewhat preoccupied facial expression with interruption of ongoing activity, although a defensive response to threatening visual stimuli was well preserved. Occasionally, the animal showed a disorganized restless behavior during the latter part of the sustained AD. From time to time, ipsilateral headturning without eye deviation was observed as though the animal was searching visually for something.

Stage 2. Slow flapping movement of contralateral forearm, head-jerking followed by repetitive contralateral headturning: A 6 to $8 \mathrm{sec}$. rhythmic flapping movement of the contralateral hand gradually propagated to the whole upper extremity which became abducted and semi-flexed at the elbow. Subsequently, this became associated with synchronized rhythmic head-jerking and shaking of the entire body. During the latter part of Stage 2 the animal developed repetitive contralateral headturning without eye deviation.
Stage 3. Hemi-convulsion beginning with sustained head-turning, conjugate eye deviation, elevation and extension of the contralateral upper extremity: This stage was characterized by the onset of sustained contralateral head-turning without eye deviation. This was followed by the gradual development of contraversive movement of the whole body associated with the tonic elevation of the contralateral upper extremity extended at the elbow. Seizure repetition resulted in the development of conjugate eye deviation, clonic jerking of the contralateral upper extremity, contralateral facial twitching, and contralateral mouth retraction. This was followed by the propagation of clonic jerking to involve the contralateral lower extremity. Postictal contralateral hemiparesis was observed at this time. There was frequent alternation of progression and regression of seizure manifestation, which was associated with a varying degree and extent of postictal paresis, often localized to the contralateral upper extremity or face. After termination of the seizure the animals usually showed marked confusion with disorganized hyperactivity and loss of response to environmental stimuli.

Stage 4. Seizure generalization with marked asymmetry: This stage was characterized by a generalization of the convulsive seizure to involve the ipsilateral body half, associated with screeching vocalization. However, the clinical seizure pattern remained markedly asymmetrical with initial contraversive and later ipsiversive movement. Even at this stage contralateral hemiparesis was clearly observed during the postictal confusional state. During the latter part of Stage 4 generalized myoclonic jerking began to emerge postictally but only when the behavioral depression was most profound.
Stage 5: Rapid generalization and bisymmetrical convulsive seizure: The final stage 5 seizure encompassed a compressed but sequential march of the ictal clinical events representing each successive stage of seizure development. Extremely rapid seizure generalization associated with the bilateral initial clonic jerking was followed by tonic flexion of the neck and extremities and sustained screeching vocalization. During the secondary clonic seizure the animal emitted rhythmic low barking vocalization. Seizure repetitions resulted in a gradual shortening of seizure duration. The latter half of the seizure was particularly affected in that the vigorous rhythmic generalized clonic jerking was replaced by irregular finer jerking which gradually dissipated and transformed into a postictal behavioral confusion instead of abrupt termination and profound inactivity. The animal was oblivious to threatening gestures or pain stimuli and remained confused and restless with licking, chewing and salivation. There was no clearly localized or lateralized postictal weakness. Postictal generalized myoclonic jerking was rare, and was observed infrequently only when the animal showed a profound behavioural depression instead of a confused state.

As shown in Figure 1 and Table 1 , a large number of stimulations (96 to 156 , average 126) were required before Stage 2 motor manifestations were observed. Similarly, over 300 stimulations were required to reach the final Stage 5 and an additional 70 stimulations were necessary to achieve the final electrographic ictal bisymmetry and bisynchrony in W136. During Stage 3 the progression of clinical seizure development was not steady with frequent alter-

TABLE I

Number of Brain Stimulations Required for Clinical Seizure Development

\begin{tabular}{|c||c|c||c|c|}
\hline \multirow{2}{*}{$\begin{array}{c}\text { Clinical } \\
\text { Seizure } \\
\text { Stage }\end{array}$} & \multicolumn{2}{c||}{ PREFRONTAL } & \multicolumn{2}{c|}{ AVERAGE } \\
\cline { 2 - 5 } & W135 & W 136 & $\begin{array}{c}\text { Prefrontal } \\
N=2\end{array}$ & $\begin{array}{c}\text { Amygdaloid } \\
\text { N=4 }\end{array}$ \\
\hline 1 & 1 & 1 & 1 & 4 \\
\hline 2 & 96 & 156 & 126 & 7.8 \\
\hline 3 & 141 & 204 & 172.5 & 11.3 \\
\hline 4 & 229 & 281 & 255 & 22.3 \\
\hline 5 & - & 318 & 318 & 72.3 \\
\hline $\begin{array}{c}\text { Final EEG } \\
\text { Bisymmetry }\end{array}$ & - & 388 & 388 & 106.8 \\
\hline
\end{tabular}


nation between early Stage 3 manifestations and hemiconvulsions. During Stages 4 and 5 there was similarly a frequent regression to the earlier Stage 3 pattern with prolonged postictal confusion associated with oral automatisms. At times there was a delayed but abrupt onset of bisymmetrical clonictonic-clonic generalized convulsions. Such a regression or aberration of an established clinical seizure pattern was frequently observed "spontaneously" but appeared also in response to a change of environment, such as the presence of a new observer or the introduction of a video tape into the laboratory.

As shown in Table 2, certain ictal clinical events such as contralateral hand flapping (Stage 2), sustained contralateral head-turning and contralateral facial twitching (Stage 3), and seizure generalization (Stage 4) remained clearly recognizable throughout the seizure development. Latencies for the onset of the Stage 3 and 4 clinical events showed progressive shortening as the seizure was repeated, indicating that much compression takes place for the development of the final stage seizure. Interestingly, no such shortening of latency was observed for the onset of the Stage 2 hand flapping.

(B) After Discharge (AD). (I) $A D$ Duration (Table 3): During Stage 1 the duration of $\mathrm{AD}$ was less than 10 seconds. There was a subsequent slow and irregular increase associated with the successive development of motor seizure manifestations with a tendency for frequent and abrupt alternation between marked prolongation and abbreviation during Stages 3 and 4. Eventually, AD duration reached an average of 51.3 seconds during Stage 4 . However, once Stage 5 was reached there was an abrupt reduction of AD duration to an average of $40.2 \mathrm{sec}$. resulting from the abbreviation of the secondary clonic convulsive component. On several occasions W136 showed prolonged AD during Stages 4 and 5 lasting longer than $80-90$ seconds. This was due to an abortive termination of the Stage 3 motor seizure which was replaced by a Stage 1 or 2 seizure pattern with delayed and abrupt onset of primary generalized convulsive seizure (Figure 6).

(2) AD Propagation: (a) Cortical involvement: Immediately poststimulation, high amplitude 20-25/sec. sustained AD developed at the stimulated site (Figure 2). From the first stimulation, synchronous $A D$ readily propagated into the contralateral homologous cortical area. The latter showed individual spikes of much sharper configuration though with lower $\mathrm{AD}$ amplitude. This was followed by progressive development of a rhythmic bilateral $6-8 / \mathrm{sec}$. AD pattern coincident with the contralateral hand flapping during Stage 2 . Subsequently, there was a gradual modification of the immediate poststimulation AD pattern at the stimulated site to a lower amplitude, slower frequency beginning at Stage 3 . This was in contrast to the contralateral homologous site which maintained multiple spike discharge throughout the seizure development. Similarly, the posterior frontal cortical area developed a low amplitude 25-30/sec. sustained spike discharge at the time of asymmetrical seizure generalization. During Stage 5, recruitment of ipsilateral prefrontal cortical fast $\mathrm{AD}$ appeared to be coincident or even secondary to generalized deep structure ictal involvement at the time of onset of Stage 3 manifestations. Thus, when the animal was kindled there was no longer high amplitude sustained fast $\mathrm{AD}$ at the stimulated cortical site immediately poststimulation.

(b) Deep structure involvement: During the latter part of Stage 1, there was a progressive and preferential dissemination of low amplitude $\mathrm{AD}$ into the ipsilateral GP, CD and MRF. Similarly, low amplitude slow synchronous activity was recorded in the ipsilateral HYPO, AM, HIPP and MD, becoming gradually bilateral by the time of the 50th stimulation. During Stage 2, semirhythmic $6-8 / \mathrm{sec}$. activity synchronous to that of cortical AD became generalized, although with higher amplitude at the GP and HIPP, ipsilaterally.

During Stage 3 the slow rhythmic $A D$ was replaced by fast sustained spike discharge in all the ipsilateral deep structures except for HYPO which continued to display slow wave discharge synchronous to that of the stimulated prefrontal cortex. Among the structures monitored, the HIPP and then the GP showed the most prominent discharge (Fig-

TABLE 2

Mean Latency (sec.) for March of Ictal Clinical Events

\begin{tabular}{|c|c|c|c|c|c|c|c|c|c|c|c|c|c|}
\hline \multirow{3}{*}{\multicolumn{2}{|c|}{$\begin{array}{l}\text { CLINICAL } \\
\text { EVENTS } \\
\text { ANIMAL }\end{array}$}} & \multirow{2}{*}{\multicolumn{2}{|c|}{$\begin{array}{l}A \cdot B \\
A=\text { End of } \\
\text { Stimulation }\end{array}$}} & \multirow{2}{*}{\multicolumn{2}{|c|}{$\begin{array}{c}\text { B - C } \\
\text { B = Stage } 2 \\
\text { Contralateral } \\
\text { Hand Flapping }\end{array}$}} & \multirow{2}{*}{\multicolumn{2}{|c|}{$\begin{array}{c}\text { C - D } \\
\mathrm{C}=\text { Stage } 3 \\
\text { Contralateral } \\
\text { Facial Twitch }\end{array}$}} & \multirow{2}{*}{\multicolumn{3}{|c|}{$\begin{array}{l}\mathrm{A}-\mathrm{D} \\
\mathrm{D}=\text { Stage } 4 \\
\text { eizure Generali- } \\
\text { ation }\end{array}$}} & \multirow{2}{*}{\multicolumn{3}{|c|}{$\begin{array}{l}\text { Duration of General- } \\
\text { ized Convulsive } \\
\text { Component }\end{array}$}} \\
\hline & & & & & & & & & & & & & \\
\hline & & $W 135$ & $W 136$ & W135 & W136 & W135 & W136 & W135 & W136 & $\mathrm{AM}$ & W135 & $W 136$ & $A M$ \\
\hline \multirow{4}{*}{ 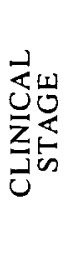 } & 2 & 5.0 & 5.0 & & & & & & & & & & \\
\hline & 3 & 4.8 & 5.2 & 16.9 & 17.6 & & & & & & & & \\
\hline & 4 & 4.5 & 4.5 & 14.5 & 11.8 & 15.0 & 6.0 & 34.0 & 22.3 & 17.5 & 22.8 & 23.5 & 35.7 \\
\hline & 5 & & 5.1 & & 7.6 & & 2.7 & & $\begin{array}{l}20.3 \\
15.4^{*}\end{array}$ & 11.9 & & $\begin{array}{l}30 \\
24.8^{*}\end{array}$ & 50.9 \\
\hline
\end{tabular}


ure 3 , top). At the time of the hemiconvulsions, high amplitude spike or multiple spike and wave discharge developed (during the latter part of the individual seizure) in the ipsilateral brain stem most prominent at the ipsilateral MRF with synchronous but blunted reflection elsewhere (Figure 3, bottom). The AD terminated simultaneously in all areas with a significant and widespread amplitude depression, although moderately high amplitude postictal irregular slow activity continued in the contralateral prefrontal

Figure 2-Stage 1 and 2 seizure development. Note initial trans-hemispheric cortico-cortical propagation.

WI36

\section{ST STIMULATION STAGE I AD DURATION 2.5 SEC}

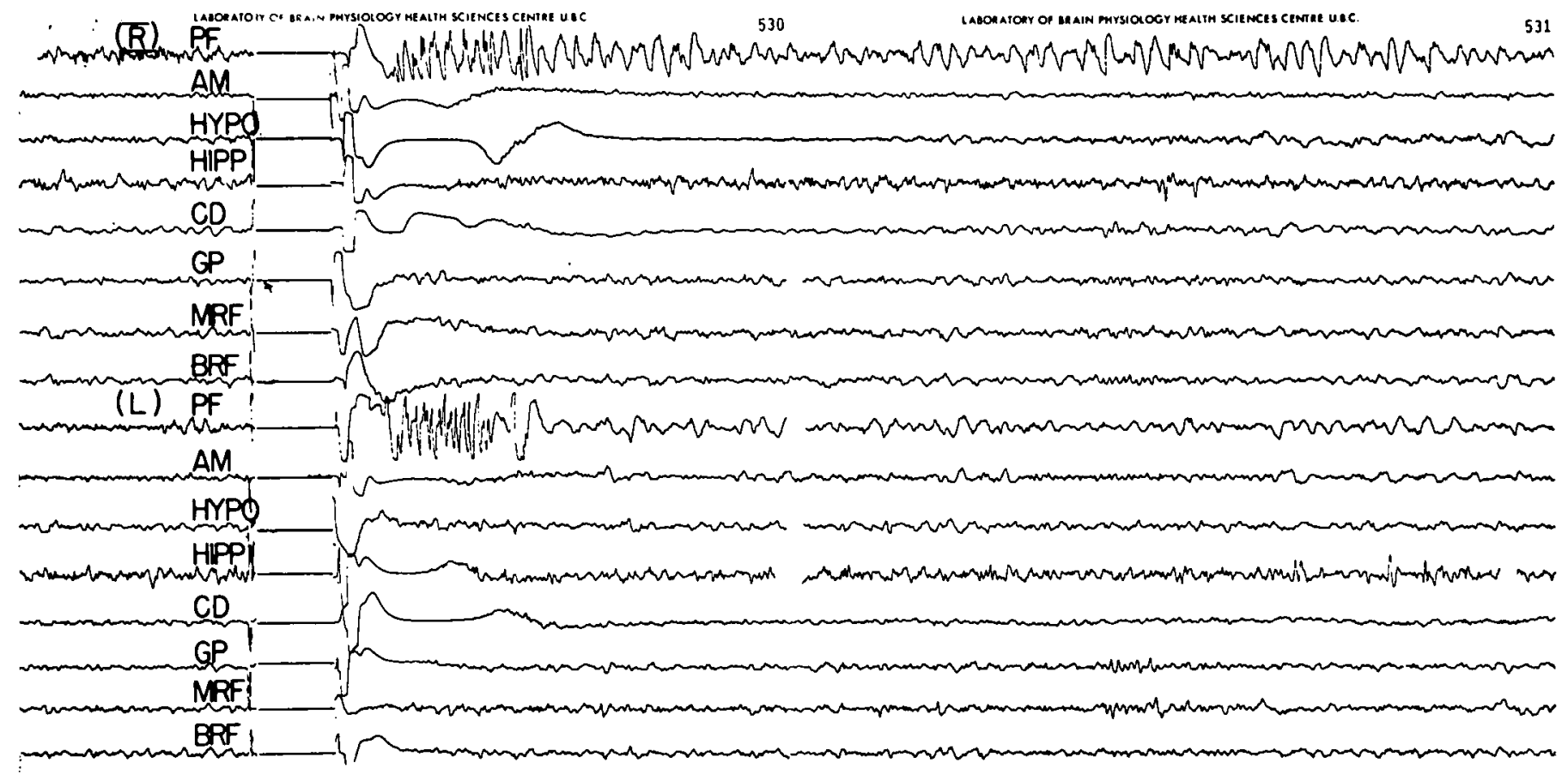

\section{TH STIMULATION STAGE 2 AD DURATION 8 SEC}

Mnumanding in

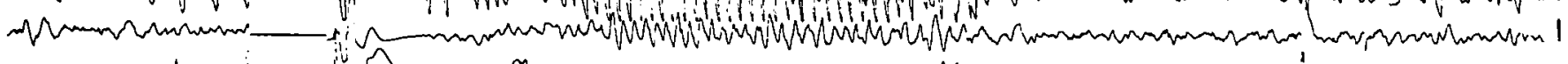

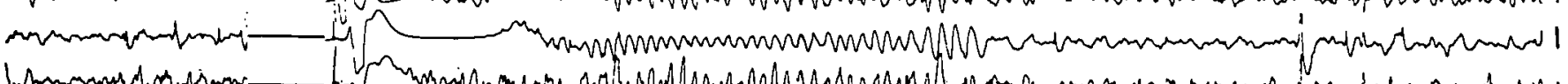

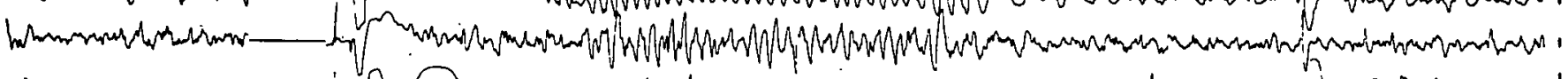

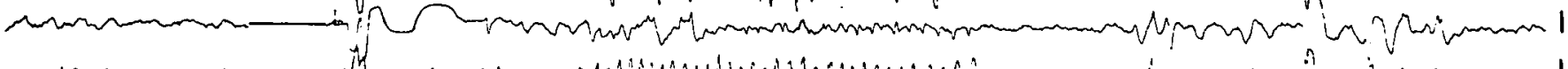

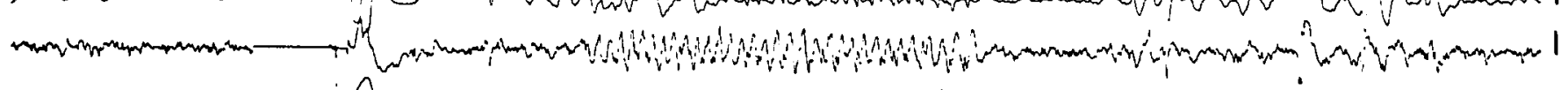

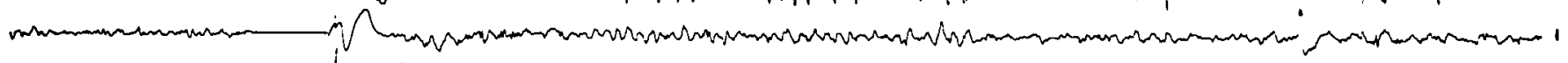

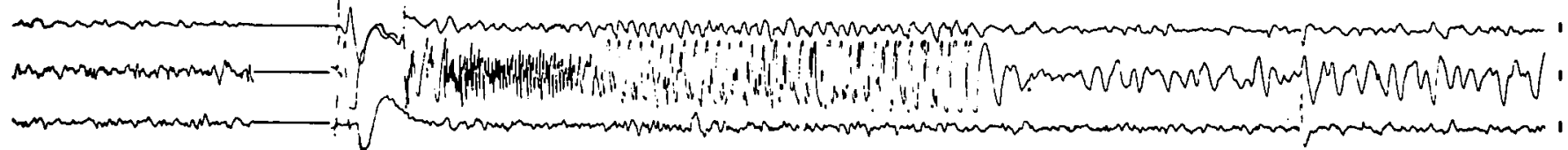

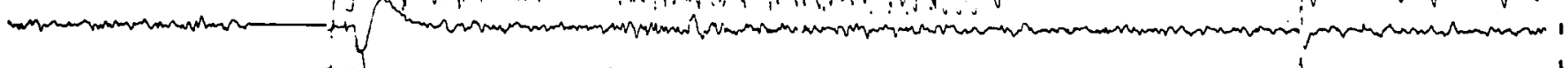

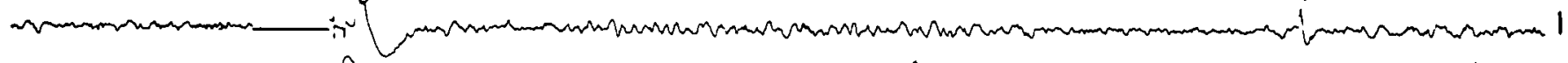

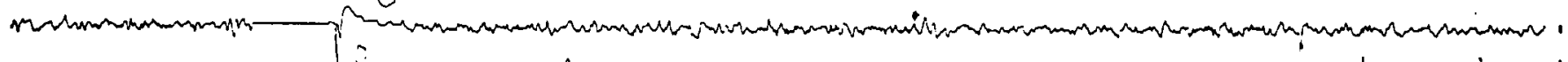
rom

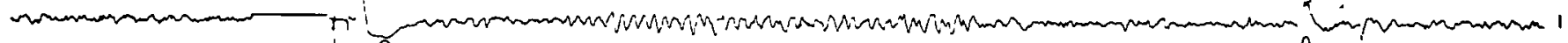

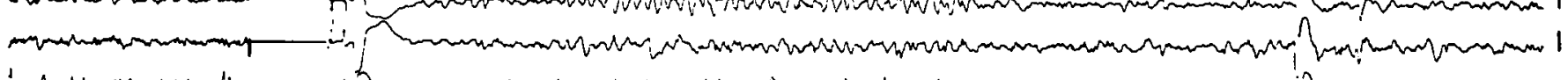

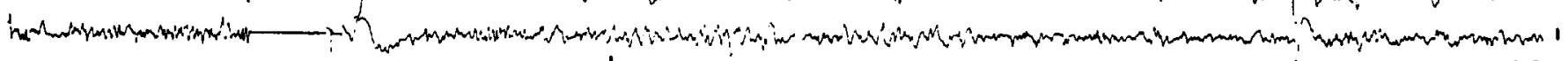
1 
cortical area and in the ipsilateral HIPP.

During Stage 4 asymmetrical seizure generalization (Fig. 4), spike or multiple spike and wave discharge at the ipsilateral MRF became widespread involving the ipsilateral HIPP, GP, SN and BRF, with somewhat delayed involvement of the contralateral homologous deep structures. At the time of seizure generalization brief bursts of high amplitude 12 to $14 / \mathrm{sec}$. generalized multiple spike discharge were recorded in the posterior frontal areas with some reflection into the deep structures. The termination of $A D$ at this stage was simultaneous in all the areas but the ipsilateral HIPP continued to show moderately high amplitude irregular slow activity. At no time was there asymmetrical growth of hemispheric AD such as that frequently observed in AM kindling. Postictally, generalized myoclonic jerking was associated with high amplitude spike or sharp and slow transients in the BRF and MRF.

The Stage 5 seizure was characterized by the progressive shortening of latency for the emergence of bilateral low amplitude, tightly organized $A D$ in the BRF. This was followed by a rapid and generalized recruitment of high amplitude fast $\mathrm{AD}$, more marked in the MRF and GP, with gradual transformation into generalized synchronous spike or multiple spike and wave during the secondary clonic stage. During Stage 5 abrupt AD termination was very frequently replaced by gradual
AD dissipation and diffuse irregular postictal slow activity associated with prolonged confused behavior (Figure 5). At this time, only the HIPP and prefrontal cortices continued to show sharp or spike components of somewhat higher amplitude. The marked and abrupt generalized postictal amplitude depression associated with emergence of myoclonic jerking was observed only rarely. Although the lalatency for the onset of the BRF discharge was usually $10-15 \mathrm{sec}$. it was not uncommon to observe a marked delay with a latency of $50 \mathrm{sec}$. or more. Under such circumstances, the ipsilateral HIPP was the only structure that showed a sustained but irregular $\mathrm{AD}$ prior to the onset of the bilateral BRF discharge (Figure

Figure 3-Stage 3 seizure development. Note development of multiple spike and wave discharge in the ipsilateral MRF and BRF at the time of hemi-convulsion (bottom).

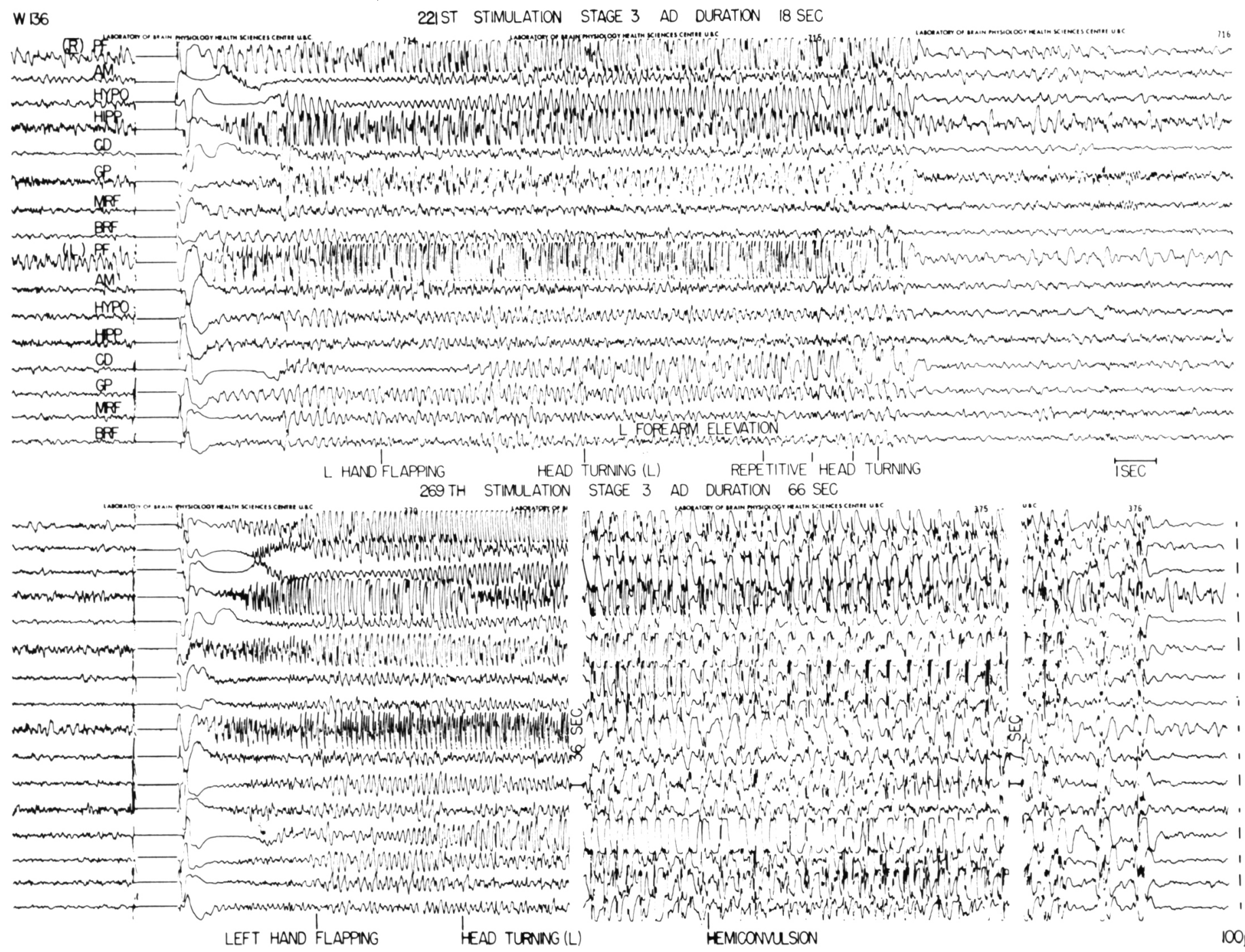


6). Termination of AD was abrupt and simultaneous in all structures, but at times irregular AD at the ipsilateral HIPP outlasted the seizure (Figure 5). This was coincident with oral automatisms, salivation, pupillary dilation and visual searching behavior.

(3) Chronological change in the background EEG activity: (a) Cortical surface: During Stage 1 there was an emergence of moderate to moderately high amplitude $3-4 / \mathrm{sec}$. semi-rhythmic slow activity, at times interlocked with sharp components in the frontal regions. Such activity became continuous during Stage 2 and was not influenced by eye opening or attention focusing factors. However, during the latter part of Stage 2 there was a tendency for the slow wave activity to appear as a sporadic burst, losing its continuity before finally being replaced by paroxysmal bursts of $3-5 / \mathrm{sec}$. irregular slow activity during Stage 3-4. During Stage 5 the cortical slow activity became less rhythmic, reflecting generalized irregular slow background activity.

(b) Deep structures (Figure 7): During Stage 3 spikey $10-13 / \mathrm{sec}$. rhythmic activity was observed, particularly in the ipsilateral GP, which gradually propagated to involve the ipsilateral MRF and then the contralateral basal ganglia and brain stem structures during Stage 4. During Stage 5 there was a disintegration of this rhythmic activity to irregular low to moderately high amplitude, somewhat slower, semi-rhythmic activity. Subsequently, when the animal began to show spontaneous generalized convulsive seizures there was an emergence of almost continuous and bilateral spikey rhythmic $10-13 / \mathrm{sec}$. burst activity in the MRF and BRF. The animal also began to display an episodic violent, behavioral aberration in the background of a continuously confused behavior state. This brain stem EEG burst activity, however, gradually subsided in the four months following termination of brain stimulation, coincident with the progressive improvement of the behavior pattern and the eventual disappearance of the episodic aberration and confused state.

(4) Interictal discharge (IID) (Figure $8)$ : IID, with an amplitude of 400 $1000 \mu \mathrm{V}$ and of isolated biphasic spike morphology, was persistently recorded at least 14 hours following the last brain stimulation in all areas except the BRF and GP during kindling. IID developed first in stimulated PF during Stage 1 and later in contralateral PF during Stage I (W 135) or Stage 2 (W136). In spite of a

Figure 4-Stage 4 asymmetrical generalized convulsion. Upper and lower tracings are continuous.
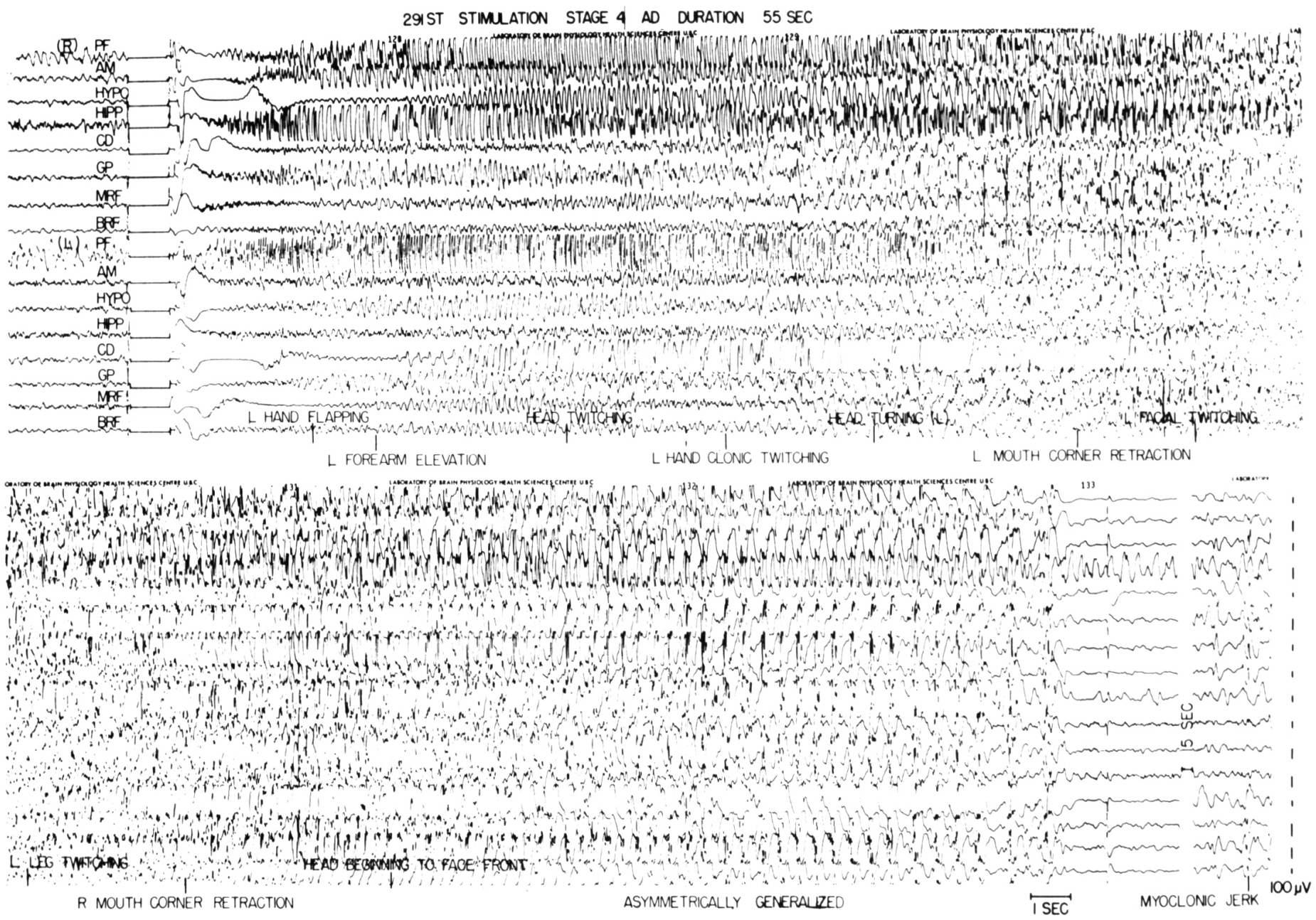
slightly delayed development, IID frequency at the contralateral PF was somewhat higher than at the stimulated PF during subsequent periods of seizure development. This was due to the development of independent IID contralaterally.

Among the deep structures, the GP, MRF and HIPP showed a substantial increase in IID frequency reaching their peaks between Stages 3-5. However, a marked change in the background EEG pattern in these structures as mentioned already made identification and quantification of IID difficult. During the early stages, IID tended to appear independently from different sites but synchronized IID within the stimulated hemisphere began to emerge during Stage 3. With further stimulation, all IID tended to appear synchronously in either one or both hemispheres. Throughout the seizure development IID frequency was lower in contralateral structures than in ipsilateral structures except for the prefrontal cortex which showed an independent increase contralaterally. Since IID was rarely seen during the waking state but frequently during the drowsy state, all night recordings were made after the animal had reached Stage 5 of seizure development. The sleep EEG pattern was classified into 5 stages according to the following criteria.

Sleep Stage 0: Resting wakefulness. Generalized low amplitude activity with $10-13 / \mathrm{sec}$. rhythmic sharp bursts in the MRF and BRF. IID was present only very infrequently.

Sleep Stage 1: Frequency of the rhythmic brain stem sharp bursts became somewhat slower with intermingling of high amplitude sharp activity. High amplitude spike or multiple spike discharge often associated with a slow wave component appeared initially in the PF ipsior contralaterally and often independently. Lateralized or generalized bursts of high amplitude spike, multiple spike and wave discharges were recorded, entirely independently from the cortical surface in the basal ganglia and brain stem ipsilaterally or bilaterally.

Sleep Stage 2: The background pattern showed some increase in rhythmicity over sleep Stage 1 and there was an emergence of high amplitude $11-13 / \mathrm{sec}$. sustained and bilateral spike burst lasting for $2-3 \mathrm{sec}$. in the PF area although better or-

Figure 5-Stage 5 bisymmetrical generalized convulsion.

(A) $\mathrm{W} 136$

345 TH STIMULATION StAGE 5 SEIZURE DURATION 24 SEC
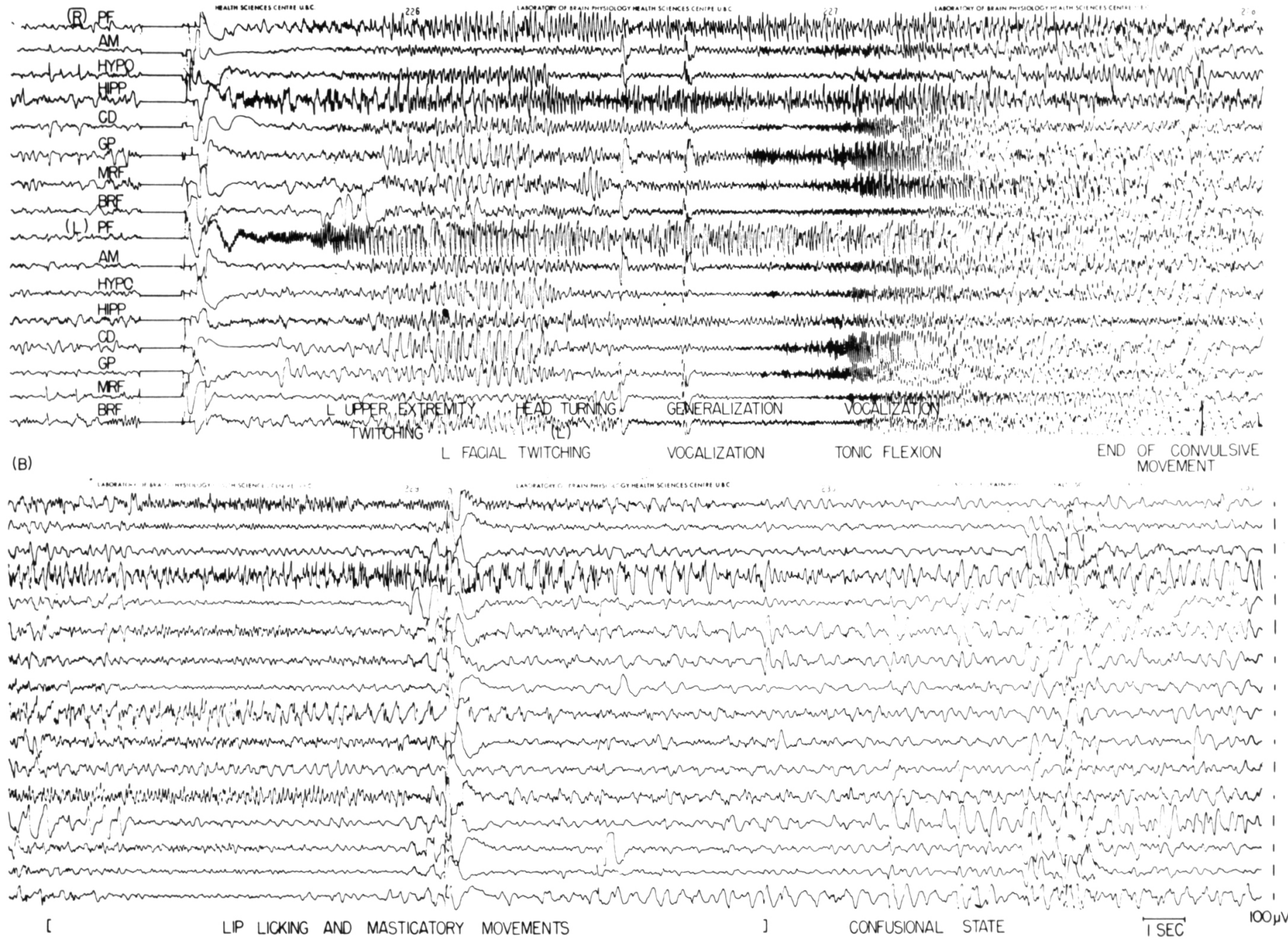
ganized contralaterally. Among the cortical areas, multifocal IID was present within both frontal cortical areas.

Sleep Stage 3: The 11-13/sec. spike burst at PF was transformed into $20-25 / \mathrm{sec}$. low amplitude tightly organized burst activity though more marked contralaterally. Rhythmic sharp bursts in the brain stem were no longer identifiable.

Sleep Stage 4: The onset of this
Stage was characterized by generalized and rather abrupt flattening of the background activity without $10-12 / \mathrm{sec}$. brain stem burst activity. This EEG pattern was associated with a slight twitching of

Figure 6-Delayed onset of stage 5 seizure. Note early onset of low amplitude AD in the BRF (8th and 16th channels, middle tracing). All tracings are continuous.

W 136

38 I St Stimulation StAGE 5 SEIZURE DURATION 79 SEC

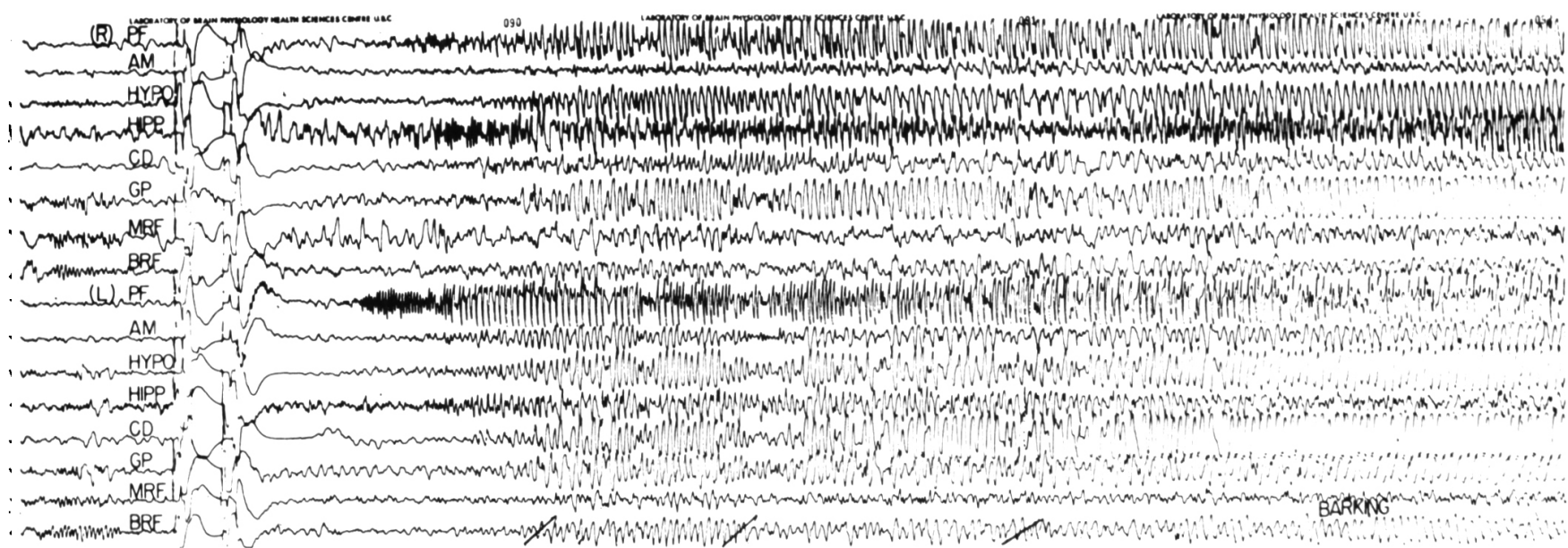

RESTLESS BARKING L HANC FLAPPING L HEAD-BODY ADVERSION L UPPER EXTREMTY EXTENDED AND ELEVATED

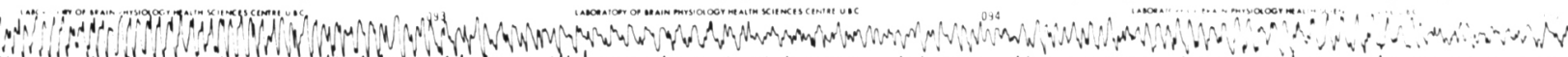

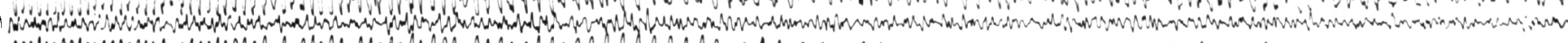

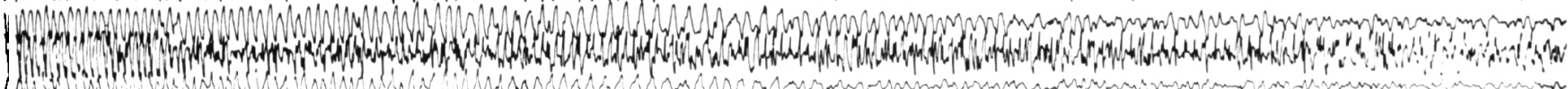

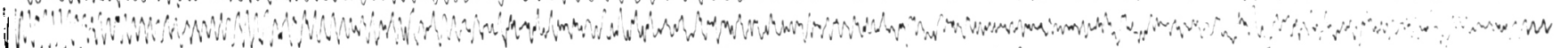

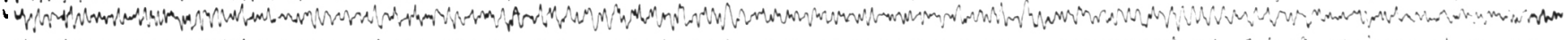

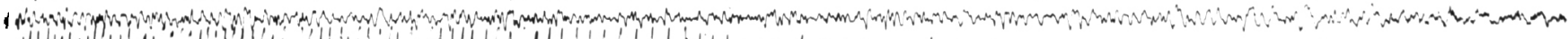

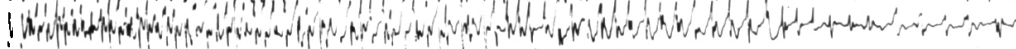

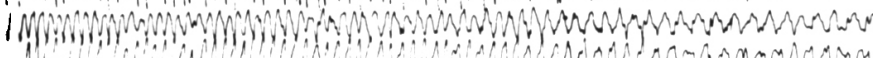

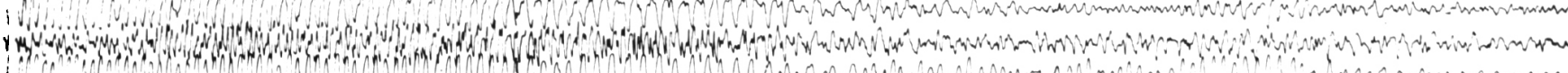

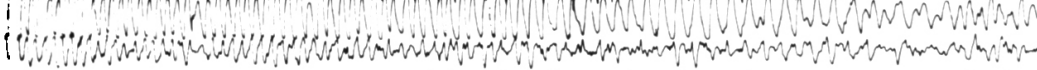

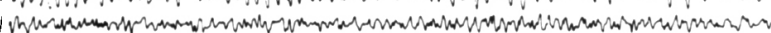

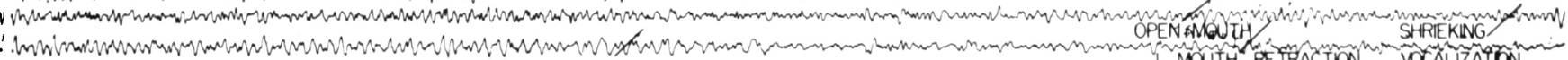

REPETITIVE BARKING

L UPPER EXTREMITY TWITCHING END REPETITIVE LICKING

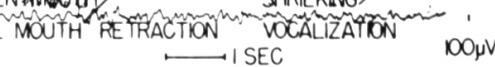

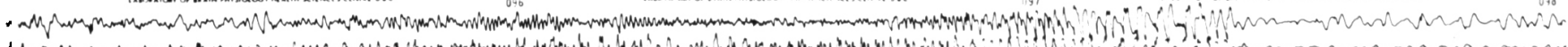

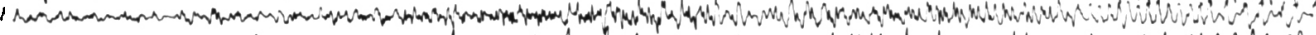

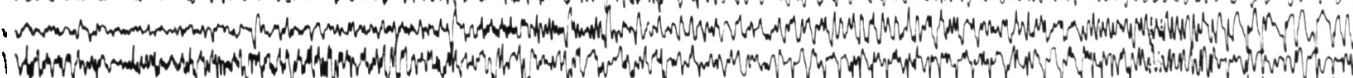

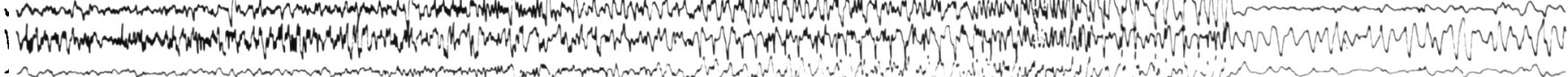

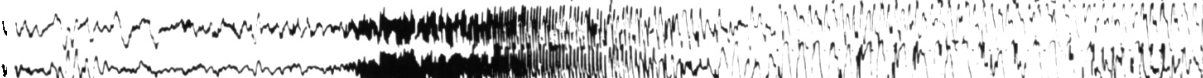

inn

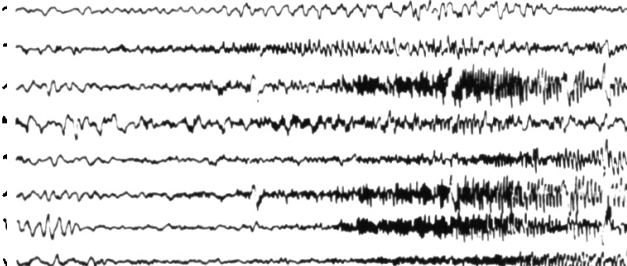

INITIAL CLONIC GENERALIZED TONIC FLEXION

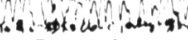

SECONDARY CLONIC

SYMMETRICAL

END CONVLLSION

CONFUSIONAL STATE 
Figure 7-Interictal background EEG pattern.

\section{CHRONOLOGY OF BACKGROUND PATTERN}

\section{WI36 \\ STAGE | (16TH) \\ LABORATORY OF BRAIN PHYSTOLOCY MEALTH SC}

(B) PF

$A M$

HYPO

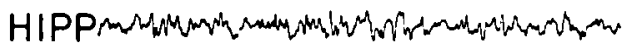

CD

GP

MRF

BRF

(L) $P F$

AM

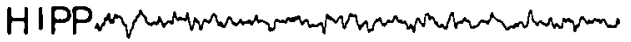

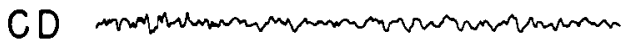

GP

MRF

BRF

STAGE 4 (307TH)

'MYSIOLOCY MEAITM SCIENCES CENTRE UBC

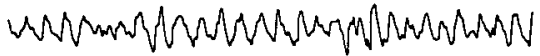

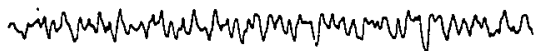

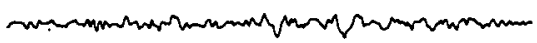

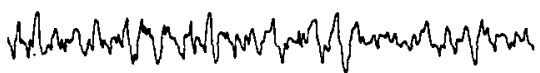

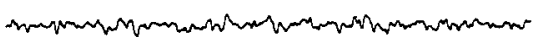

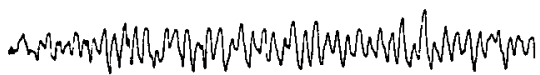

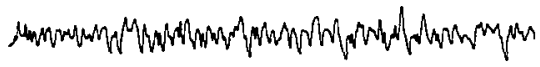

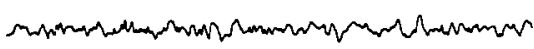

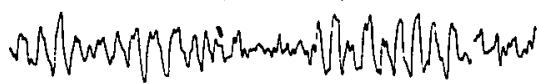

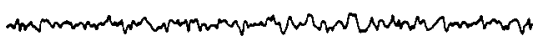

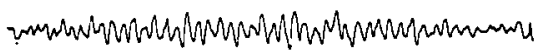

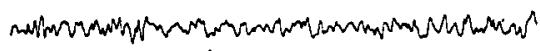

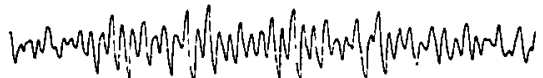

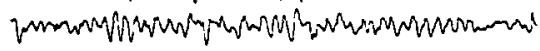

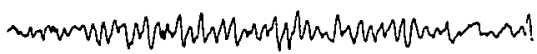

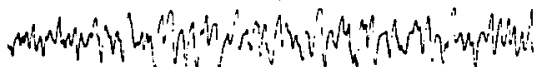

\section{STAGE 2 (179TH)}

LABORATORY OF BRAIN PMYSIOLOCY HEALIM SCIENCES CENTRE

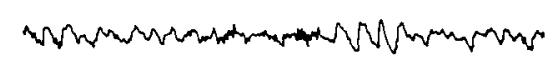

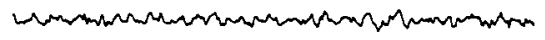
was

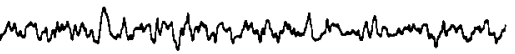

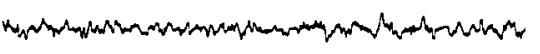

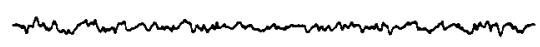

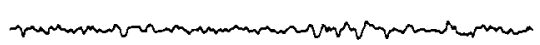

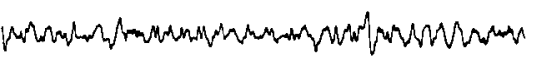

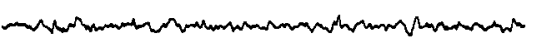
roven

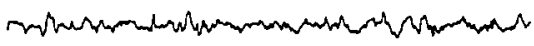

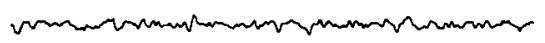

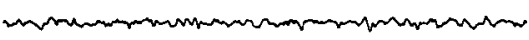

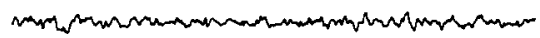

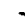

\section{STAGE 5 (325TH)}

LABORATORY OF BRAIN PHYSIOTOGY MEALTH SCIENCES!

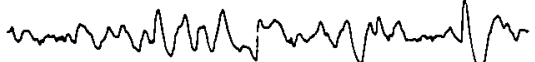

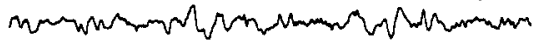

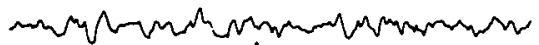

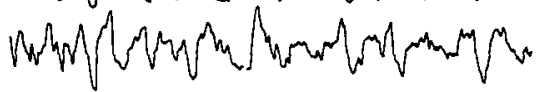

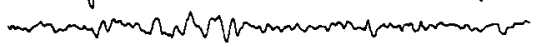

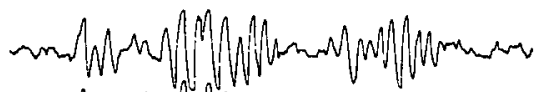

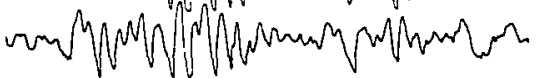

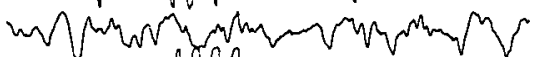

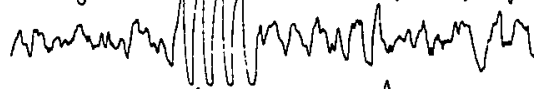

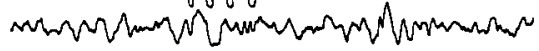

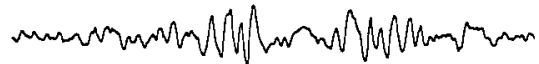

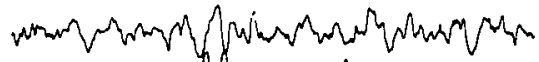

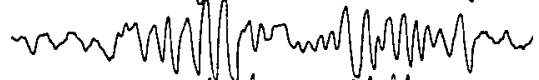

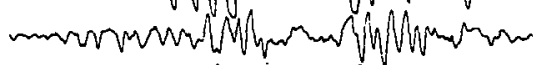

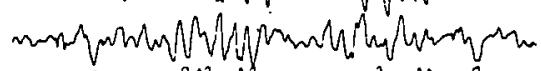

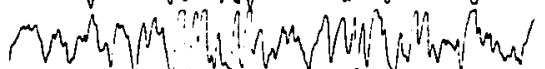

STAGE 3 (232ND)

YWEATIH SCIENCES CENTRE UBC.

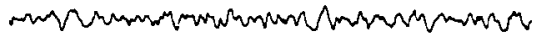

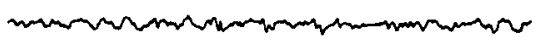

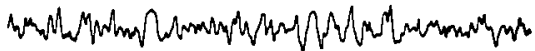

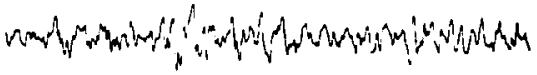

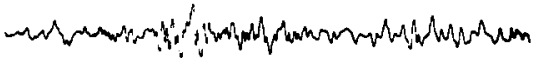

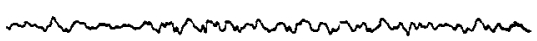

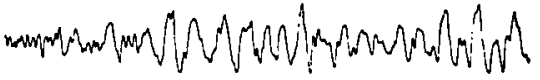

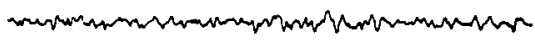

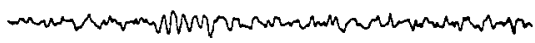

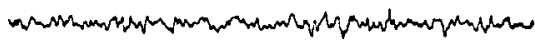

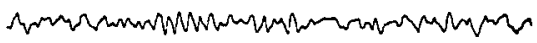

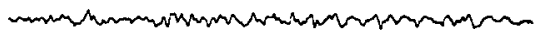

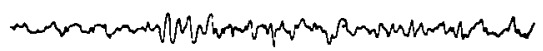

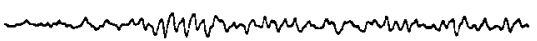

STAGE 5 (375TH) LABORATORY OF BRAIN PHYSIOLOGY

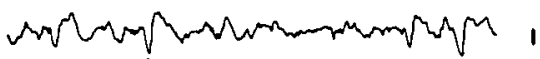

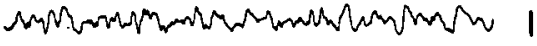

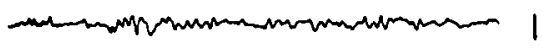

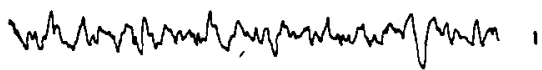

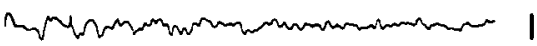

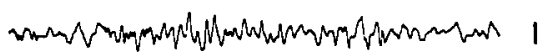

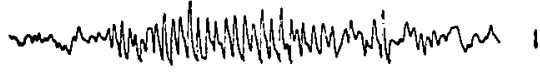

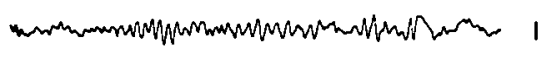

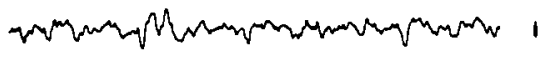

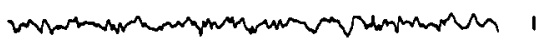

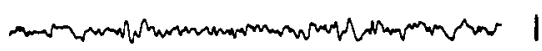

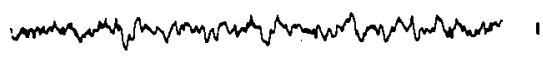

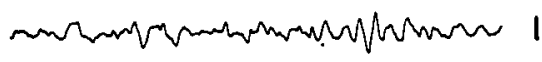

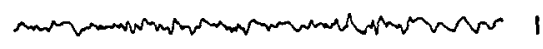

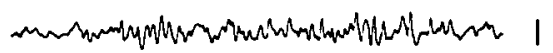

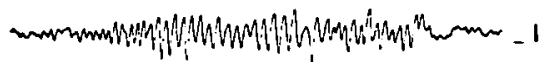

-I SEC- 10OUV 
the neck, shoulders and extremities as well as rapid eye movement.

The results of sleep examination confirmed that IID was best identified during drowsiness to light sleep. No IID was present during Stage 4 or rapid eye movement sleep.

(5) Spontaneous Seizures: Twelve spontaneous seizures were witnessed during Stage 5 (W136). The first five seizures were identified during the daytime, 4-11 hours after the last brain stimulation. These seizures were generalized convulsions but no electrographic monitoring or detailed observation of their clinical onset was possible. However, it is interesting that the first spontaneous seizure occurred right after the com-
TABLE 3

AD Duration (sec.) of Seizures Induced By $P F$ and AM Stimulation During Kindling

\begin{tabular}{|c|c|c|c|c|}
\hline \multirow{2}{*}{$\begin{array}{c}\text { Clinical } \\
\text { Seizure } \\
\text { Stage } \\
\end{array}$} & \multicolumn{3}{|c|}{ PREFRONTAL } & \multirow{2}{*}{$\begin{array}{c}\text { AMYGDALOID } \\
\text { Mean } \\
N=4 \\
\end{array}$} \\
\hline & W135 & W136 & $\begin{array}{l}\text { Mean } \\
\mathrm{N}=2\end{array}$ & \\
\hline 1 & $\begin{array}{r}7.7 \\
\pm 1.6 \\
\end{array}$ & $\begin{array}{r}6.9 \\
+2.9 \\
\end{array}$ & 7.3 & 18.2 \\
\hline 2 & $\begin{array}{r}10.5 \\
+\quad 2.6\end{array}$ & $\begin{array}{r}12.8 \\
+\quad 4.0\end{array}$ & 11.9 & 27.5 \\
\hline 3 & $\begin{array}{r}18.4 \\
\pm \quad 3.3 \\
\end{array}$ & $\begin{array}{r}30.4 \\
\pm \quad 7.6 \\
\end{array}$ & 24.4 & 39.5 \\
\hline 4 & $\begin{array}{r}56.8 \\
\pm 11.4 \\
\end{array}$ & $\begin{array}{r}45.8 \\
\pm \quad 4.2 \\
\end{array}$ & 51.3 & 53.2 \\
\hline 5 & - & $\begin{array}{r}50.3 \\
\pm 13.8 \\
40.2 \\
\pm \quad 6.2 \\
\end{array}$ & $\begin{array}{c}50.3 \\
(40.2)^{*}\end{array}$ & 62.7 \\
\hline
\end{tabular}

*excluding atypically prolonged seizure

Figure 8-Emergence of interictal discharge during sleep.

W.136

SLEEP STAGE 0

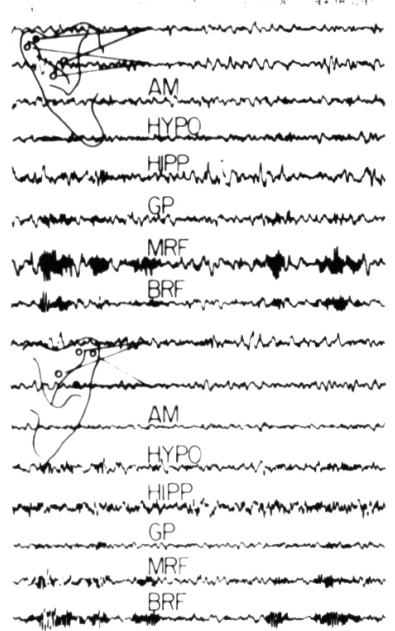

SLEEP STAGE I

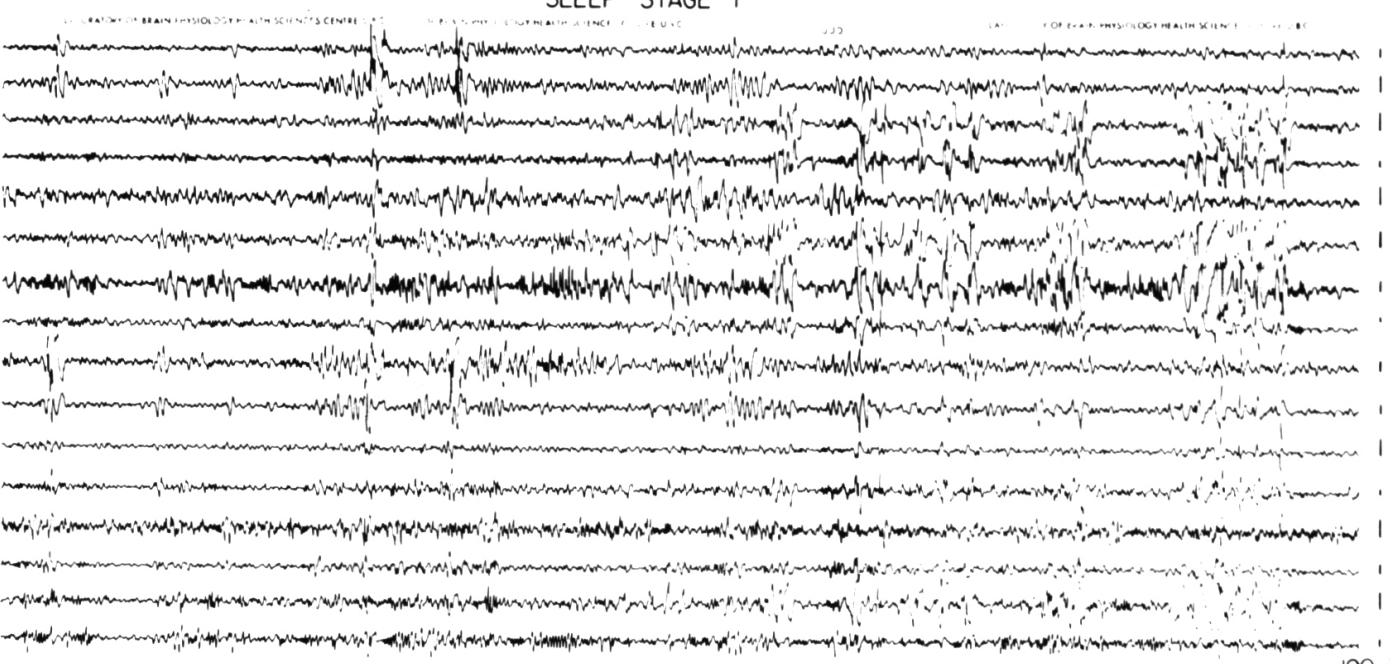

$\overline{2 \mathrm{SEC}}$
SLEEP STAGE 2

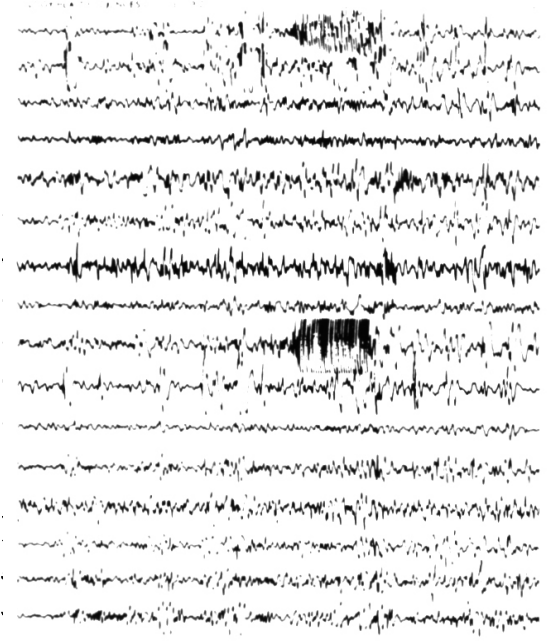

SLEEP STAGE 3

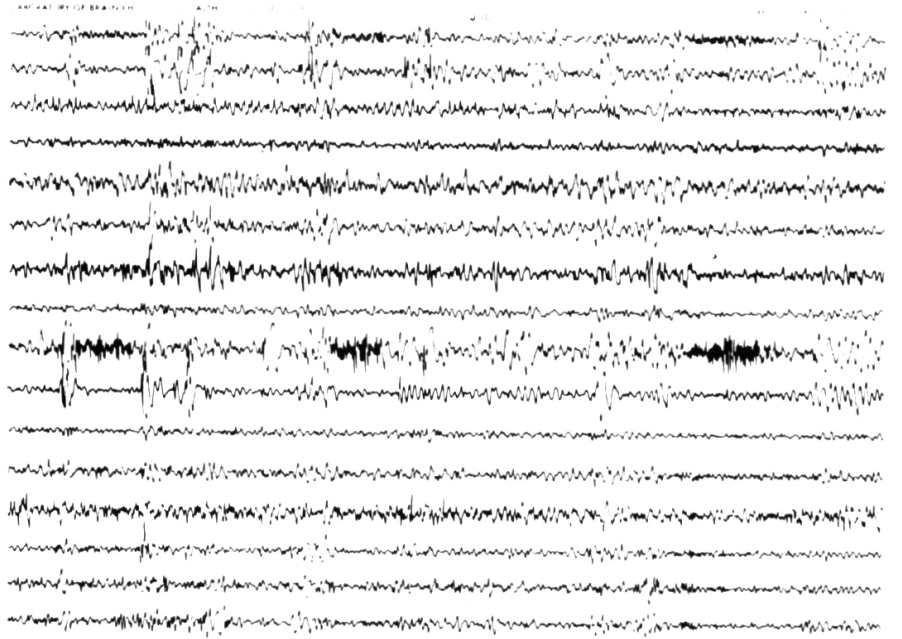

SLEEP STAGE 4

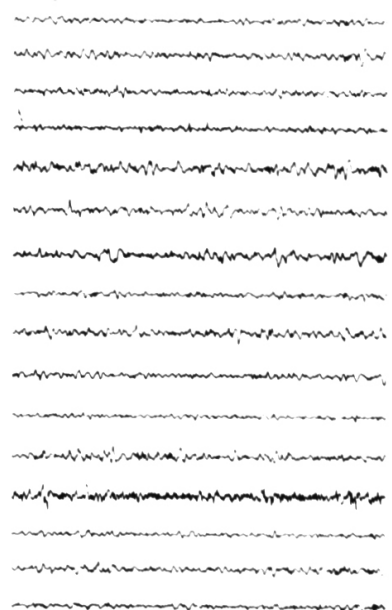


Figure 9-Spontaneous seizure of focal onset. Note striking similarity to induced seizure (fig. 6). All tracings are continuous.

W 136

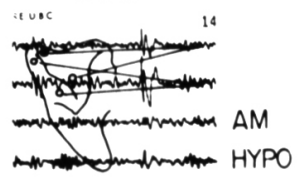

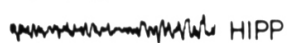

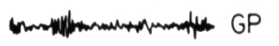

MRF
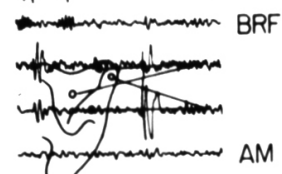

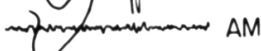

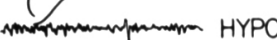

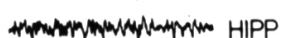

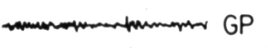

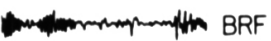

Unmmanosutmermans MRF

SPONTANEOUS GENERALIZED SEIZURE

245 AM MAY 25, 1974

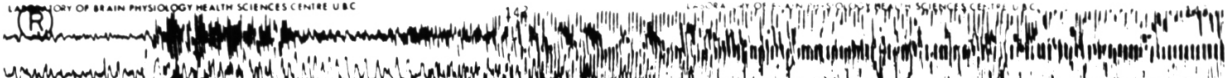

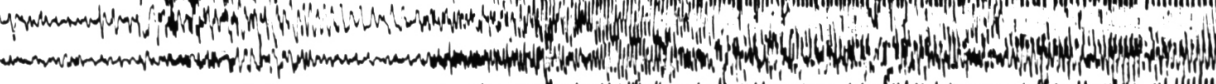

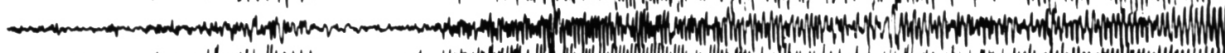

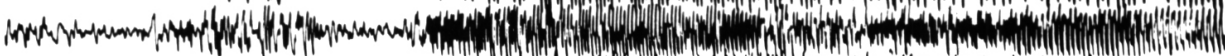

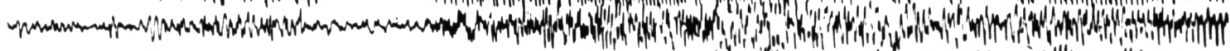

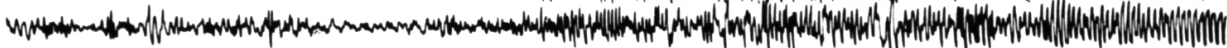

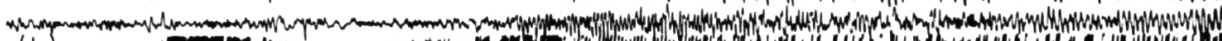
(s)

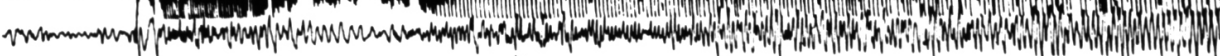

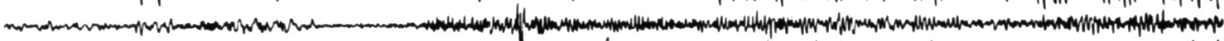

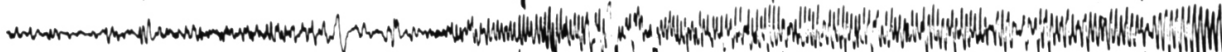

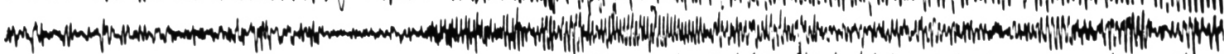

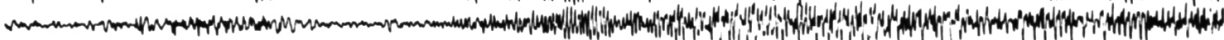

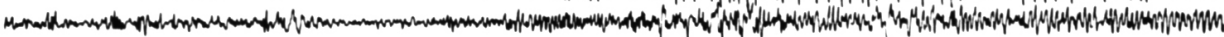

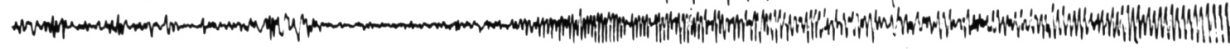

$\stackrel{2 \text { SEC }}{2}$

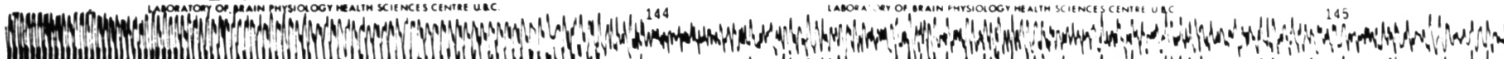
(9. 10.

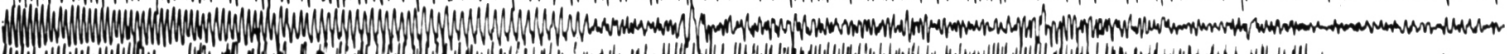
.

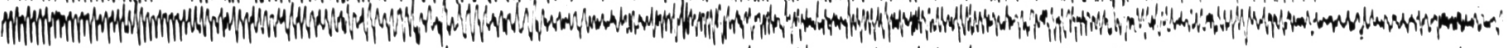

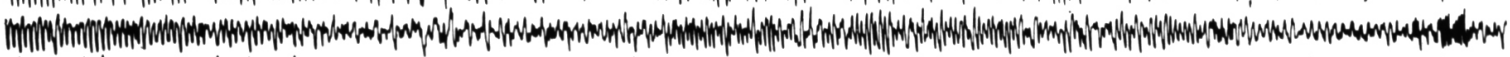

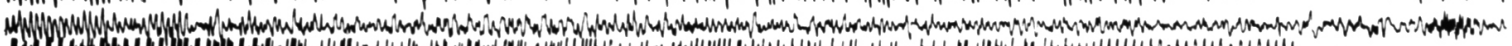

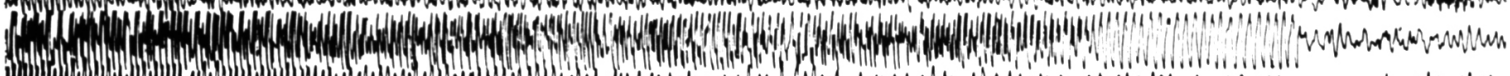

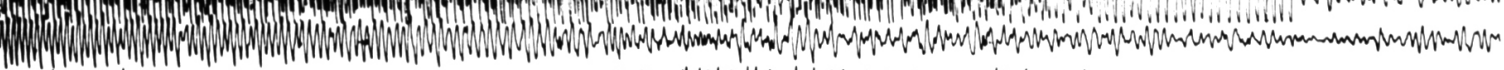

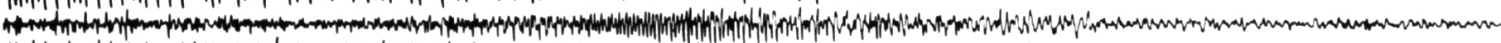

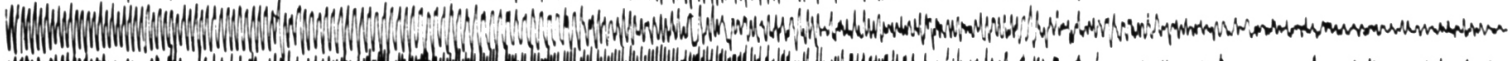

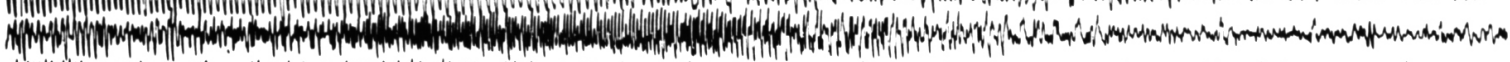

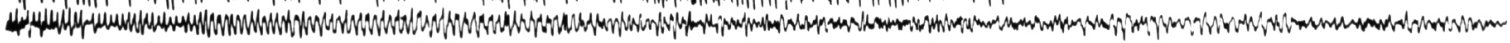

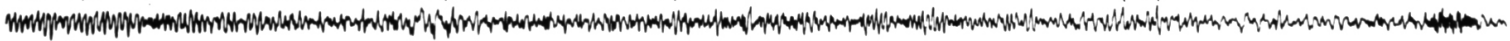

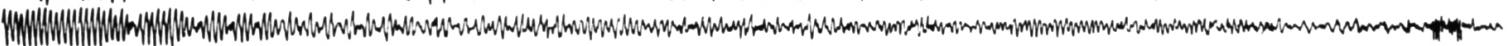

(C)

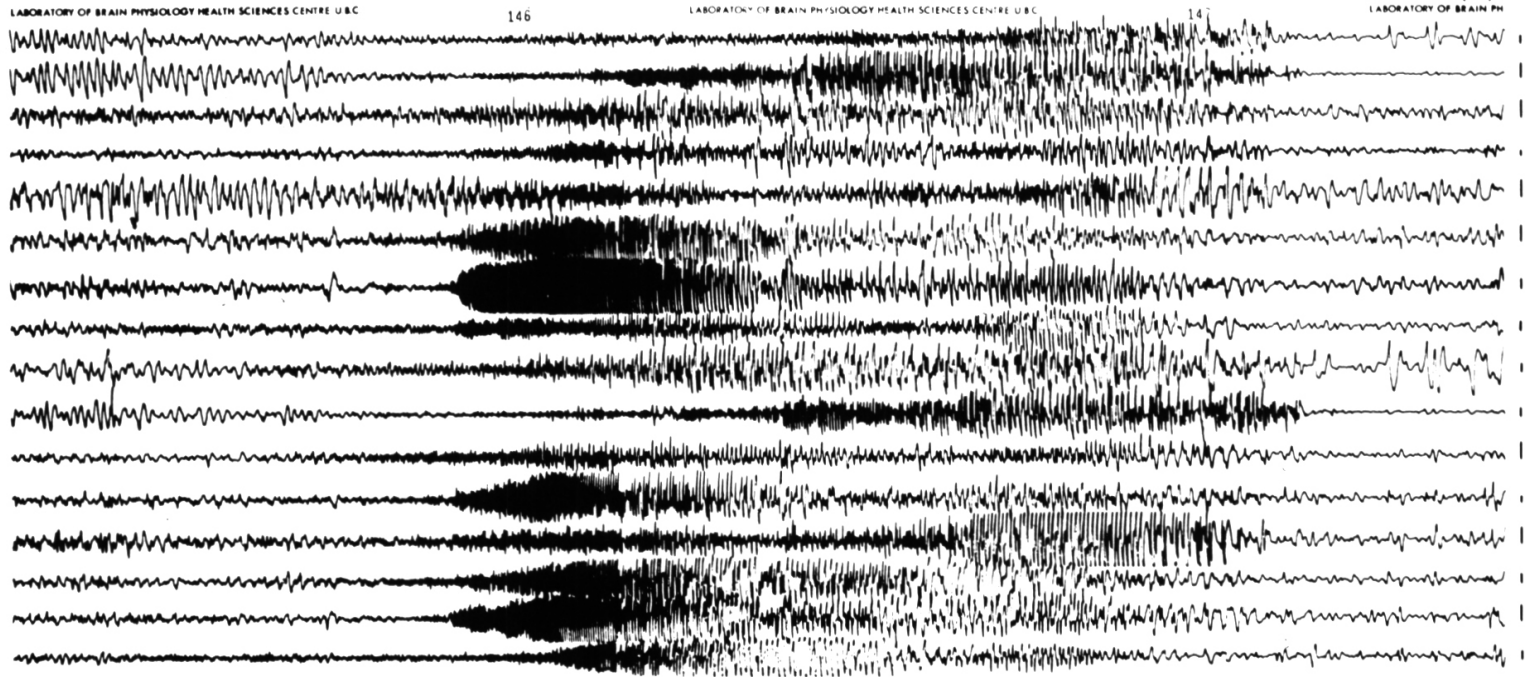


pletion of Stage 4 seizure development. The remaining seven spontaneous seizures were witnessed during continuous EEG monitoring lasting for 27 hours beginning at 9:00 p.m. and carried out 4 days following the last (389th) PF stimulation that produced a Stage 5 seizure.
Examination of the EEG data obtained during this period suggested that all the witnessed spontaneous seizures occurred during sleep Stage 1 except for the first one which began with a clear focal prefrontal discharge during sleep Stage 2 with prolonged delay of the onset of bisymmetrical Stage 5 seizure (Figure 9). This pattern is strikingly similar to that of an induced Stage 5 seizure (Figure 6). All the other seizures were of abrupt nonfocal onset with electroclinical manifestations identical to that portion which characterized Stage 5 and could be

Figure 10-Spontaneous seizure of generalized onset. Note early onset of low amplitude AD in the BRF. Upper and lower tracings are continuous.

W 136 SPONTANEOUS GENERALIZED SEIZURE

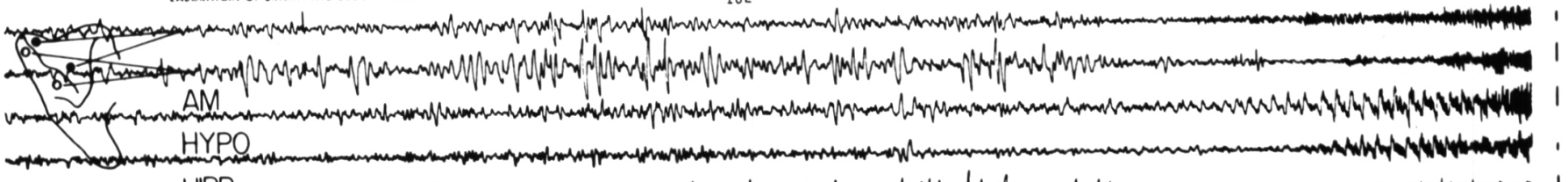

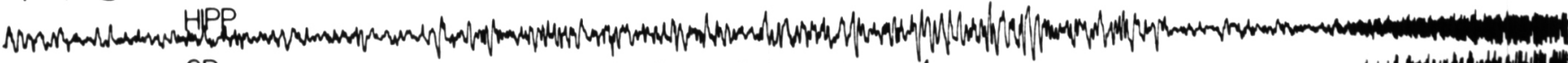
GP

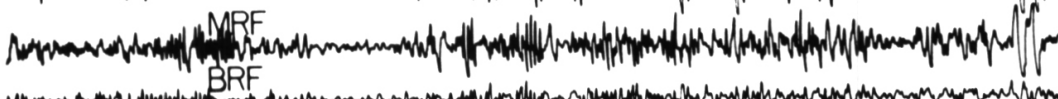

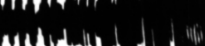
14. (1) (n)

$\longmapsto 2$ SEC

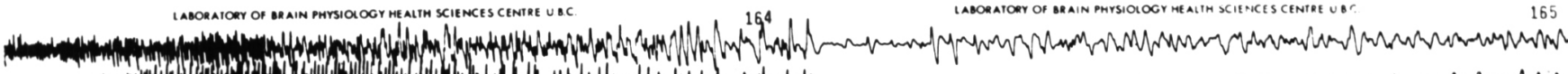
165

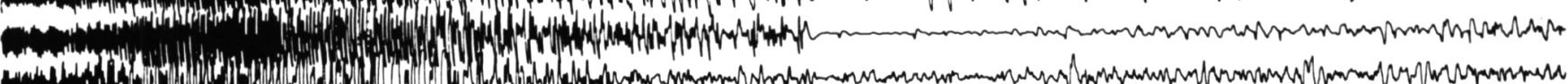

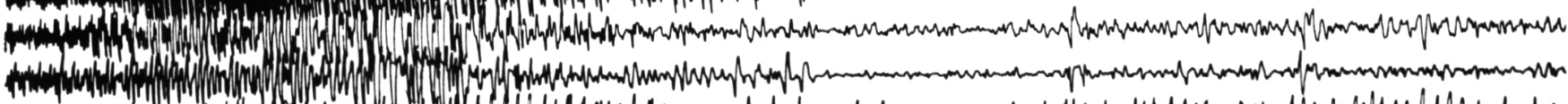

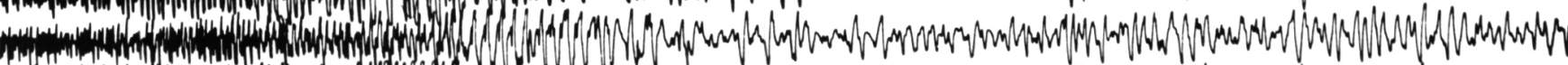

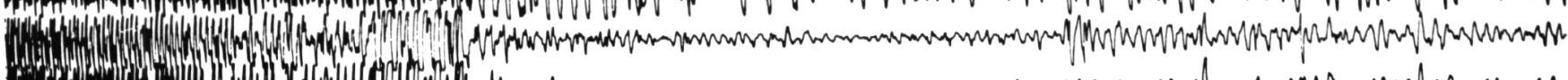

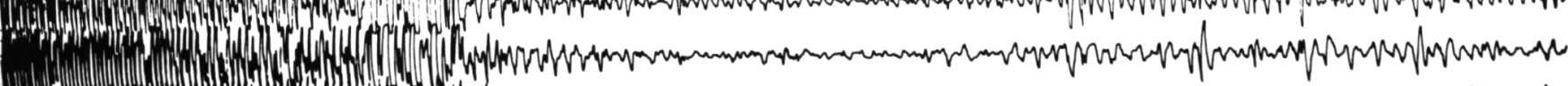

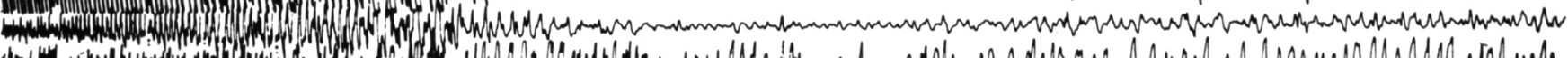

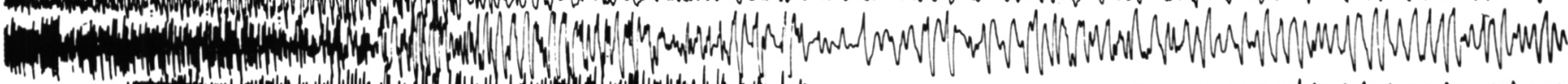
(n)

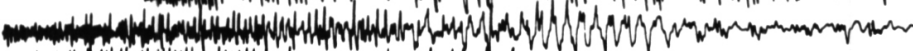

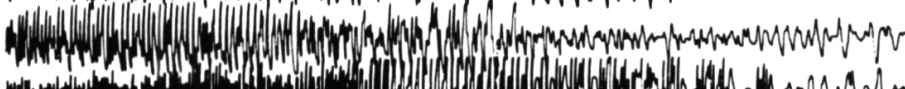

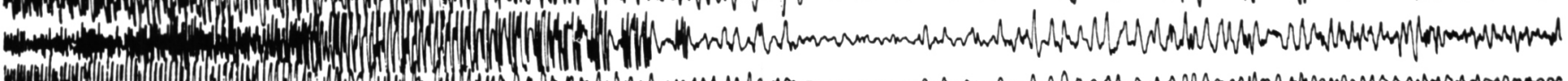

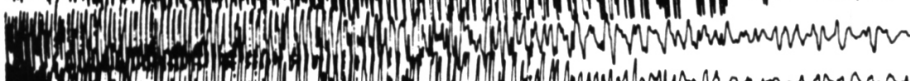

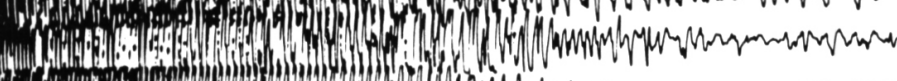
烈

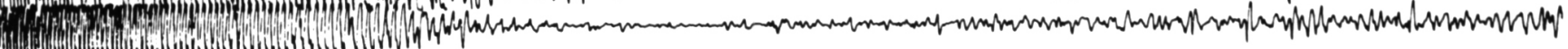


most appropriately termed as a primary generalized seizure (Figure $10)$. The duration of the seizure with focal onset was long, lasting for 114 sec., but the duration of the generalized seizures was short with a range of $31-48 \mathrm{sec}$. and an average of $38.5 \mathrm{sec}$. As in the case of induced Stage 5 seizures the tonic spontaneous seizure progressed to fine irregular clonic movements of the whole body which gradually dissipated and was transformed into dazed, restless, confused behavior.

(6) Generalized seizure triggering threshold (GST): The initial stimulus intensity that produced the first AD was $700 \mu \mathrm{a}$ in both animals. This intensity was used continuously until Stage 5 seizure development was reached. GST examination in W136 showed the critical threshold to be $200 \mu$ a. When the animal was stimulated below the critical GST it was generally not possible to induce any electroclinical seizure manifestations. However, stimulation at the GST frequently evoked earlier stage seizures suggesting that the prefrontal stimulation had not acquired an "all or none" property after the completion of Stage 5.

(7) Interictal behavioral aberration: W136 developed frequent episodes of violent biting of its collar plate and screaming lasting 30-60 sec. following Stage 5 seizure development. This was always associated with initial head turning toward the right. The frequency of this behavior gradually decreased following termination of the prefrontal stimulation and it was no longer observed at 4 months. There has not been any recurrence of this behavior during a subsequent period of 7 months without further stimulation. The chronology of the episodic behavior was temporally related to a spikey $10-13 / \mathrm{sec}$. rhythmic bursting in the brain stem. Similarly, generalized slowing of the background activity prevailing during Stage 5 seizure development was no longer present one month following the termination of the prefrontal stimulation.

(8) Photosensitivity: Following the termination of the PF kindling in W136, the clinical intensity and electrographic correlates of photosen- sitivity were unchanged compared to the prekindling period, with a range of $\mathrm{C}+0$ to $\mathrm{C}+3$ response.

\section{DISCUSSION}

The present study demonstrated that Papio papio can be kindled from the PF culminating in a recurrent spontaneous convulsive seizure state identical to that observed in AM kindled Papio papio. The unique feature of PF kindling was the large number of stimulations required (an average of 156) for the development of focal contralateral motor seizure manifestations. This finding contrasts with that of an average of 7.8 stimulations required for the same manifestations in AM kindling in this species. The findings suggest a closer functional linking from AM than from PF to motor mechanisms responsible for the onset of focal motor seizures. It is interesting in this respect to note the differences in pattern of motor seizure development between prefrontal and amygdaloid kindling. While the order of the contralateral motor seizure development in the former was the upper extremity, head-turning and facial twitching, the order in the latter was head turning, facial twitching and the upper extremity. The fact that monoparesis of the contralateral hand and face was observed in PF and AM kindling respectively suggests the likelihood that the involved motor mechanism may be rep- resented in the rolandic cortex. Possible mechanisms by which ictal events in the AM propagate to the lateral convexity of the ipsilateral hemisphere are not clear. However, the ascending pattern of ictal propagation involving the rolandic cortical somatotopic representation in AM kindling suggests an initial propagation of ictal events to the lowest rolandic portion probably via the insula buried within the Sylvian fissure ipsilateral to the stimulated amygdala. On the other hand, the initial ictal involvement of the upper extremity in PF kindling suggests transmission of the responsible discharge into the midportion of the rolandic strip possibly via corticocortical connections.

As summarized in Table 4, considerable differences exist between seizure manifestations resulting from kindling of $\mathrm{PF}$ and of $\mathrm{AM}$. Among the differences noted, the extreme sensitivity with which the $\mathrm{PF}$ preparation tended to respond to environmental stimuli contrasts with that of a relatively stable seizure state induced by AM kindling. The finding that a large number of PF stimulations are required to develop ictal motor manifestations, coupled with the lack of reduction in latency for the initial hand flapping throughout the seizure development, suggest that PF kindling involves the sequential activation of multisynaptic neuronal networks before the

TABLE 4

Differential Features between Amygdaloid $(A M)$ and Prefrontal (PF) Kindled Stage 5 Seizure

\begin{tabular}{|c|c|c|c|}
\hline \multicolumn{2}{|c|}{ Clinical Feature } & PF & $\mathrm{AM}$ \\
\hline \multicolumn{2}{|c|}{ Stability of Established Seizure } & \pm & +++ \\
\hline \multicolumn{2}{|c|}{ Secondary Clonic Convulsion } & $\begin{array}{l}\text { Less Intense } \\
\text { \& Shorter }\end{array}$ & Vigorous \\
\hline \multicolumn{2}{|c|}{ Seizure Termination } & Gradual & Abrupt \\
\hline \multirow{4}{*}{ Post-Ictal } & Depression (EEG) & \pm & ++ \\
\hline & Coma & - & +++ \\
\hline & Myoclonic Jerk & \pm & ++ \\
\hline & Confusion & ++ & \pm \\
\hline \multicolumn{2}{|c|}{ Inter-Ictal Behavioral Aberration } & + & - \\
\hline \multicolumn{2}{|c|}{ Spontaneous Seizure } & + & + \\
\hline
\end{tabular}


common motor pathway responsible for the onset of a focal motor seizure is reached. Another significant difference between AM and PF kindling is the occurrence of an episodic behavioral aberration in the PF animal which was not observed in any of the four AM animals. Although this behavioral alteration was characterized by stereotyped confusion with initial head-turning suggesting its ictal nature, we were unable to observe any epileptiform electrographic abnormality during the episodes. It is quite possible that our electrode placements were not in the area where critical ictal events were taking place. On the other hand, the close chronological correlation of the onset and disappearance of this behavioral abnormality and the appearance and dissipation of brain stem sharp bursts suggest that they are interrelated events resulting from PF stimulation. The absence of this abnormality among AM kindled animals poses an interesting question since, clinically, one is accustomed to the occurrence of a variety of behavioral and perceptual disturbances among individuals with partial complex seizures of temporal lobe origin. Significant frontofugal connections to the non-specific thalamic system (Stratford, 1954; Jasper et al., 1974) and widespread intra- and interhemispheric cortical connections of the frontal lobe contrast with the powerful subcortical limbic connections of the amygdala. Ictal participation of the former may account for both episodic and postictal confusion in PF animals while ictal involvement of the latter may be primarily responsible for the pattern of profound post-ictal inactivity. Although ictal and post-ictal manifestations of partial complex seizures tend to be regarded as of temporal lobe origin, the finding of frequent psychic auras and automatisms among patients with a frontal polar epileptogenic focus (Ajmone-Marsan \& Goldhammer, 1973) necessitates increased awareness of such alternative possibility. In spite of the well accepted notion that adversive movement associated with initial loss of consciousness are ictal manifestations of clinical seizures originating from frontal polar epileptogenic foci (Penfield \& Jasper, 1954), there are enough data to suggest that some generalized convulsive seizures with no localizing or lateralizing initial signs may have their origin in the frontal lobe (Goldring, 1972; Bancaud, 1974). Since postictal confusion, rather than comatose inactivity, was the characteristic clinical feature of generalized convulsions resulting from PF stimulation in baboons as well as cats (Wake \& Wada, 1975), the presence of prolonged postictal confusion in a patient with a generalized convulsive seizure should raise suspicions of the possibility that it originates in the frontal lobe.

The pattern that characterized the Stage 5 seizure was identical in PF and AM animals with early onset of an unique $\mathrm{AD}$ in the BRF and subsequent generalized bisymmetrical tonic flexion associated with bisynchronous electrographic discharge. This finding is identical to that of the documented spontaneous primary generalized seizure in this species kindled from either the AM or PF site. In addition, the electroclinical pattern of photoconvulsive seizures observed in this species (Wada, Terao \& Booker, 1972) is strikingly reminiscent of the primary generalized seizure mentioned above. Taken together, the findings suggest that Papio papio possesses a predisposed mechanism responsible for primary generalized convulsive seizure probably integrated in the lower brain stem which can be triggered by photic, PF and AM stimulation, in addition to an unidentified source of stimulation resulting in its spontaneous onset.

The fact that Stage 5 seizure resulting from PF stimulation frequently lacked the vigorous secondary clonic convulsive component requires some comment. Profoundly confused behavior characterizing the post-ictal state of the PF kindled animal contrasts with the comatose inactivity and frequent generalized myoclonic jerkings that follow AM stage 5 convulsion. The reason for the shorter seizure duration and lack of post-ictal electrographic depression in PF Stage 5 seizures is not clear. However, it does suggest that a significant difference exists between mechanisms underlying seizure development originating from the AM and PF. Seizure stability and the progressive increase of seizure duration and intensity observed in AM kindling probably reflect a steady epileptogenic recruitment of forebrain subcortical limbic mechanisms prior to integration with the brain stem mechanism of the primary generalized seizure in Papio papio. Since there is no electrographic evidence that secondary ictal AM activation is responsible for PF seizure development, it is clear that the latter depends primarily upon ictal involvement of extralimbic forebrain mechanisms which are not necessary ingredients of vigorous secondary clonic convulsions nor profound postictal electroclinical depression. Comparisons of postictal electrographic findings between $\mathrm{AM}$ and PF kindling similarly suggest that the post-ictal myoclonic jerking is of lower brain stem origin resulting from a transient functional release from primarily inhibitory limbic forebrain mechanisms.

Although the relative paucity of IID in the PF animal contrasts with a relatively stable and prominent IID in the AM animal during the waking state, both share the common feature of remarkable IID accentuation during sleep. In our PF animal a brief burst of sustained spike discharge was recorded from the stimulated $P F$ and its contralateral homologous cortical areas; in addition, an entirely independent spike, multiple spike and wave discharge was recorded in widespread deep structures during light sleep. This finding appears to call for careful reappraisal of the clinical concept that "frontal lobe epileptiform discharges are rarely enhanced by sleep"' (Rasmussen, 1975).

The pattern of onset of the previously documented spontaneous seizures was either focal or primary generalized in nature. The former was identical to that of PF kindled seizures and the latter was identical to that portion of the seizure which 
characterizes Stage 5 in both PF and AM kindled animals. These findings suggest that the Papio papio kindling preparation is a unique and valuable model of human epilepsy exhibiting both secondary and primary generalized convulsive seizures, induced by either electrical kindling stimulation, photic stimulation, or appearing spontaneously in the background of a predisposed epileptogenic susceptibility. The fact that the degree of electroclinical photosensitivity did not change following PF kindling is consistent with our previous experience in AM kindling suggesting that the mechanisms underlying photosensitivity and primary generalized seizure are independent variables (Wada \& Osawa, 1975).

The results of the present and previous studies demonstrate that significant differences exist between $\mathrm{PF}$ and AM kindling, but that both can attain a recurrent spontaneous seizure state strikingly reminiscent of human epilepsy. Thus, the availability of this unique experimental model of epilepsy as represented by the PF as well as the AM kindled Senegalese baboon, Papio papio, should not only provide us with the opportunity to gain insight into the mechanism of epileptic activity, but also add new dimensions to the study of antiepileptic agents insofar as their prophylactic and anticonvulsant properties are concerned.

\section{REFERENCES}

AJMONE MARSAN, C. and GOLDHAMMER, L. (1973). Clinical ictal pattern and electrographic data in cases of partial seizures of fronto-central-parietal origin. In Epilepsy: Its phenomenon in Man. (Ed. M.A.B. Brazier) 236-258, University of California, Los Angeles Forms in Medical Sciences, Number 17, Los Angeles.

BANCAUD, J., TALAILACH, J., MOREL, P., BRESSON, M., BONIS, A., GEIER, E. and BUSER, P. (1974). "Generalized" epileptic seizures elicited by electrical stimulation of the frontal lobe in man. Electroencephalography and Clinical Neurophysiology, 37, 269-274.

GODDARD, G. V., McINTYRE, D. C. and LEECH, C. K. (1969). A permanent change in brain functions resulting from daily electrical stimulation. Experimental Neurology, 25, 295-330.

GOLDRING, S. (1972). The role of prefrontal cortex in grand mal convulsion. Archives of Neurology, 26, 109-119.

JASPER, H., AJMONE MARSAN, C and STOLL, J. (1952). Cortico-fugal projections to the brain stem. American Medical Association Archives of Neurology and Psychiatry, 67, 155-166.

KAADA, B. R and JOHANNESSEN, N. B. (1960). Generalized electrocortical activation by cortical stimulation in the cat. Electroencephalography and Clinical Neurophysiology, 12, 567-573.

KRETTECK, J. E. and PRICE, J. L. (1974). A direct input from the amygdala to the thalamus and the cerebral cortex. Brain Research 67: 169-174.

NAUTA, W. J. H. (1962). Neural associations of the amygdaloid complex in the monkey. Brain $85,505-520$.

NAUTA, W. J. H. (1964). Some efferent connections of the prefrontal cortex in the monkey. In: The frontal granular cortex and behavior. (Eds. Warren/Akert) 397-409, McGraw-Hill, New York.
PENFIELD, W. and JASPER, H. (1954). Epilepsy and the functional anatomy of the human brain. p. 150, Little, Brown and Company, Boston.

RASMUSSEN, T. (1975). Surgery of frontal lobe epilepsy. In: Advances in Neurology, Vol. 8: Neurosurgical management of the epilepsies. (Eds. D. P. Purpura, J. K. Penry and R. D. Walter). p. 197-205, Raven Press, New York.

STRATFORD, J. (1954). Cortico-thalamic connections from gyrus proreus and first and second sensory areas of the cat. Journal of Comparative Neurology, 100, 1-14.

TERAMOTO, H. (1974). An experimental study on psychomotor epilepsy - the functional relationship and differentiation between mediodorsal thalamic nucleus, anteroventral thalamic nucleus and the cingulate gyrus. (Japanese). Psychiatria et Neurologia Japonica. 76/6, 319-320.

WADA, J. A. (1961). Permanent ventricular canula, simplified electrode system and behavioral observation box for the macaca monkey. Electroencephalography and Clinical Neurophysiology, 13, 298-301.

WADA, J. A., TERAO, A. and BOOKER, H. E. (1972). Longitudinal correlative analysis of epileptic baboon, Papio papio. Neurology, 22, 1272-1285.

WADA, J. A., SATO, M. and McCAUGHRAN, 7 (In Press). Cortical electrographic correlates of amygdaloid seizure development in rats, cats and baboons. Folia psychiatrica et Neurologica Japonica.

WADA, J. A. and OSAWA, T. (In press). Generalized convulsive seizure state induced by daily electrical amygdaloid stimulation in Senegalese baboon, Papio papio. Neurology.

WADA, J. A., MIZOGUCHI, T. and OSAWA, T. (Unpublished data). Progressive seizure development by daily electrical stimulation of amygdala in rhesus monkeys.
Discussion of this paper follows the paper of Corcoran et al. 